\title{
Mechanical Behavior of Gamma-Met PX under Uniaxial Loading at Elevated Temperatures and High Strain Rates
}

\author{
Mostafa Shazly and Vikas Prakash \\ Department of Mechanical and Aerospace Engineering \\ Case Western Reserve University \\ Cleveland, $\mathrm{OH} 44106-7222$ \\ Susan Draper \\ NASA Glenn Research Center \\ Cleveland, $\mathrm{OH} 44135$
IJSS - Internatiunal Jownel of
Solids c.e stratumes
Elsener

This report is a preprint of an article submitted to a journal for publication. Because of changes that may be made before formal publication, this preprint is made available with the understanding that it will not be cited or reproduced without the permission of the author. 


\begin{abstract}
Gamma titanium aluminides have received considerable attention over the last decade. These alloys are known to have low density, good high temperature strength retention and good oxidation and corrosion resistance. However, poor ductility and low fracture toughness have been the key limiting factors in the full utilization of these alloys. More recently, a new generation of gamma titanium aluminide alloys, commonly referred to as Gamma-met PX, has been developed by GKSS, Germany. These alloys have been observed to have superior strength and better oxidation resistance at elevated temperatures when compared with conventional gamma titanium aluminides.
\end{abstract}

The present paper discusses results of a study to understand the uniaxial mechanical behavior in both compression and tension of Gamma-Met PX at elevated temperatures and high strain rates. The compression and tensile tests are conducted using a modified split-Hopkinson bar apparatus at test temperatures ranging from room temperature to $900^{\circ} \mathrm{C}$ and strain rates of up to $3500 \mathrm{~s}^{-1}$. Under uniaxial compression, in the temperature range from room to $600^{\circ} \mathrm{C}$, the flow stress is observed to be nearly independent of test temperature. However, at temperatures higher than $600^{\circ} \mathrm{C}$ thermal softening is observed at all strain rates with the rate of thermal softening increasing dramatically between $800^{\circ} \mathrm{C}$ and $900^{\circ} \mathrm{C}$. The room temperature tensile tests show negligible strain-rate dependence on both yield stress and flow stress. With an increase in test temperature from room to $900^{\circ} \mathrm{C}$, the material shows a drop in both yield and flow stress at all levels of plastic strain. However, the measured flow stress is still higher when compared to nickel based super-alloys and other gamma titanium aluminides under similar test conditions. Also, no anomaly in yield stress is observed up to $900^{\circ} \mathrm{C}$.

\title{
KEY WORDS
}

Gamma Met PX, dynamic compression tests, dynamic tensile tests, elevated temperature. 


\section{INTRODUCTION}

Gamma titanium aluminides $(\gamma$-TiAl) are targeted as a material substitute for nickel and iron based superalloys (LeHolm, Clemens and Kestler, 1999) for critical propulsion components in the $600^{\circ} \mathrm{C}$ to $900^{\circ} \mathrm{C}$ temperature range. Compared with titanium alloys, they present several advantages such as higher elasticity modulus, lower density, better mechanical behavior with temperature and higher oxidation resistance by formation of a surface passive alumina layer. However, these properties come at the expense of tensile ductility, which is typically in the range of 1 to $3 \%$. As a result these intermetallics show poor crack-propagation resistance, and in contemplating the use of $\gamma$-TiAl in airfoils the threat of high-velocity small particle impacts is of considerable concern (Wright, 1993; Austin, Kelly and McAllister, 1997). The absence of plasticity at classical fabrication temperatures is also a source of difficulty, in particular, in rolling $\gamma-\mathrm{TiAl}$ into thin sheets or foils.

Gamma based titanium aluminides have an aluminum level of 45-52 atomic \%. Within this regime, there are two phases of interest; $\gamma$-TiAl ordered phase with face center tetragonal (f.c.t) $\mathrm{L1}_{0}$ crystal structure with alternating (002) planes of Ti and $\mathrm{Al}$ atoms (Young-Won Kim, 1989; Dimiduk et al., 1991; Kim and Dimiduk, 1991; Yamagushi, 1993; Recina, 2000; Lui and Stiegler, 2002), and ordered $\alpha_{2}-\mathrm{Ti}_{3} \mathrm{Al}$ phase with the $\mathrm{DO}_{19}$ hexagonal close packed (h.c.p) crystal structure (Djanarthany, Viala and Bouix, 2001; Millett, Gray and Bourne, 2000) In an attempt to improve the mechanical properties of gamma titanium aluminides, Plansee AG of Austria has developed a new generation of gamma titanium alloys called Gamma Met PX. Gamma Met PX is available in both sheet and rod forms. This product is unique, because it is suitable for both propulsion and airframe components. Moreover, it has better rolling characteristics and improved post-rolling mechanical properties. It does not need the costly fabrication processes typically used for other intermetallic components (thin sheet processing cost is $10 \%$ of other gamma titanium alloys). Shaping and forming can be carried out at relatively low temperatures to produce parts which are more uniform than those obtained with other methods. In summary the main advantages of the $\gamma$-Met alloys are (a) $\gamma$-Met alloy is $15 \%$ lighter than titanium alloys and more than 50\% lighter than superalloys, (b) it withstands temperatures that are approximately $300^{\circ} \mathrm{C}$ higher than those for titanium alloys, (c) its specific stiffness is 
approximately twice that of titanium alloys and superalloys (based on modulus normalized with respect to density), (d) it exhibits high acoustic attenuation due to high specific stiffness, and (e) fabrication costs associated with $\gamma$-Met alloys are potentially the same as for titanium alloys and superalloys (Venskutonis, 2000).

A substantial amount of research has been conducted in the past on conventional gamma titanium aluminides to characterize their mechanical properties as a function of microstructure and chemical composition at various test temperatures and strain rates. For example, Huang and Hall (1991) studied the effect of aluminum content on tensile properties and the brittle to ductile transition (BDT) behavior. Bartels et al. (1995) have studied the effect of low strain rates and temperatures on the flow behavior of Ti-48Al-2Cr with equiaxed microstructure. Liu et al. (1995) studied the quasi-static tensile properties of $\mathrm{Ti}-47 \mathrm{Al}-2 \mathrm{Cr}-2 \mathrm{Nb}$ in three different microstructures with different annealing conditions. From these studies it is now understood that the fully lamellar microstructure shows a slight drop in strength up to test temperatures of $800^{\circ} \mathrm{C}$, and then a substantial drop above $800^{\circ} \mathrm{C}$. However, this brittle to ductile transition temperature (BDTT) could not be inferred from fracture morphology. For duplex microstructures, a moderate drop in strength was observed up to $600^{\circ} \mathrm{C}$, followed by a sharp drop at temperatures higher than $600^{\circ} \mathrm{C}$. The BDTT was found to be around $700^{\circ} \mathrm{C}$, with a ductility of $117.6 \%$ at $1000^{\circ} \mathrm{C}$. Kumpfert et al. (1995) studied the effect of strain rate on the fracture morphology using 3-point bend specimens. They found that the fracture morphology was sensitive to the material microstructure, test temperature and the applied strain rate. Das and Clemens (1999) studied the effect of strain rate and temperature on Ti-47Al-2Cr-0.2Si with equiaxed $\gamma / \gamma \alpha_{2}$ lamellar colonies. They found the yield stress to decrease slowly with increasing test temperatures up to $600^{\circ} \mathrm{C}$, and then fall sharply after $600^{\circ} \mathrm{C}$. The strain to failure was also observed to increase sharply between $500^{\circ} \mathrm{C}$ and $600^{\circ} \mathrm{C}$, suggesting that BDTT to be below $600^{\circ} \mathrm{C}$. Increasing the strain rate from $10^{-4}$ to $10^{-2} \mathrm{~s}^{-1}$, resulted in an increase in yield stress and a corresponding decrease in the strain to failure. Wang et al. (1999a) studied the effect of strain-rate and temperature on the tensile behavior of $\mathrm{Ti}-47 \mathrm{Al}-2 \mathrm{Mn}-2 \mathrm{Nb}$ in nearly lamellar microstructures. They also observed an increase in yield stress with a corresponding decrease in strain to failure as the strain rate was increased from $10^{-5}$ to $10^{-1} \mathrm{~s}^{-1}$. 
In the past little work has been done in the area of high-strain-rate deformation of $\gamma$-TiAl at elevated temperatures. Jin et al. (1995) studied the dynamic as well as the quasi static properties of $\mathrm{Ti}-46.5 \mathrm{Al}-2 \mathrm{Cr}-3 \mathrm{Nb}-0.2 \mathrm{~W}$ with fine duplex microstructure. In their study they showed that at a strain rate of $2000 \mathrm{~s}^{-1}$ the material showed a yield anomaly at $600^{\circ} \mathrm{C}$. Maloy and Gray III (1996) studied the high strain rate properties of duplex microstructures of $\mathrm{Ti}-48 \mathrm{Al}-2 \mathrm{Cr}-2 \mathrm{Nb}$ in compression. Their study showed that Ti-48-2-2 has a yield stress anomaly at approximately $600^{\circ} \mathrm{C}$. However, in the work of Gardiner et al. (1997) on duplex microstructures of Ti-38.5Al2.7Nb-2.6Mn, no yield-stress anomaly was observed. The material showed high levels of strain hardening at all levels of plastic strain and at all test temperatures employed in the tests. Moreover, thermal softening was observed as the test temperature was increased above the room temperature. In tests performed between $700^{\circ} \mathrm{C}$ and $800^{\circ} \mathrm{C}$ and at strain rates of approximately $2500 \mathrm{~s}^{-1}$, cracking and fracture was observed at macroscopic plastic strains of 0.32 . However, at temperatures below $700^{\circ} \mathrm{C}$ no micro- and/or macro- cracking were observed. Vaidya et al. (1999) studied the properties of Ti-25Al-10Nb-3V-1Mo at strain rates of $10^{-3}$ and $3000 \mathrm{~s}^{-1}$ and at temperatures from $-196^{\circ} \mathrm{C}$ to $1000^{\circ} \mathrm{C}$. At a strain rate of $10^{-3} \mathrm{~s}^{-1}$ and temperatures of $1000^{\circ} \mathrm{C}$, the flow stress was observed to initially increase with strain and is then followed by strain softening. At strain rate of $3000 \mathrm{~s}^{-1}$, the flow stress was observed to increase with strain and was higher than that observed at $10^{-3} \mathrm{~s}^{-1}$. Strain hardening was observed to be independent of test temperatures except above $950^{\circ} \mathrm{C}$, where softening was observed. Yield anomaly in flow stress was observed to be around $600^{\circ} \mathrm{C}$ at strain rates of $10^{-3} \mathrm{~s}^{-1}$. However, no yield anomaly was observed at strain rates of $3000 \mathrm{~s}^{-1}$. Wang et al. (1999b) studied the high-strain-rate tensile properties of both duplex and fully lamellar microstructures of $\mathrm{Ti}-47 \mathrm{Al}-1.5 \mathrm{Cr}-.5 \mathrm{Mn}-2.8 \mathrm{Nb}$ at room temperature. Contrary to the observations of Maloy and Gray III (1996), they showed that the strength of duplex microstructures of Ti-48-2-2 decreases with increasing strain rates. However, for fully lamellar microstructures, they showed that the strength of the material increased with increasing strain rates. Wang et al. (1999c) also conducted high-strain-rate experiments on nearly lamellar microstructures of $\mathrm{Ti}-47 \mathrm{Al}-2 \mathrm{Mn}-2 \mathrm{Nb}$. They also observed increasing material strengths with increasing strain rates. More recently, Bartels et al. (2002) investigated the mechanical properties of $\gamma$-TiAl based alloy with fully lamellar microstructure under both quasi-static and dynamic loading conditions. The tests were conducted at room 
temperatures and strain rates ranging from $5.0 \times 10^{-3} \mathrm{~s}^{-1}$ to $4.0 \times 10^{3} \mathrm{~s}^{-1}$. The results of the compression tests showed slight strain-rate sensitivity of the post yield stress.

The present paper presents results of a study to understand the uniaxial behavior of Gamma-Met PX alloy developed by GKSS, Germany. Uniaxial compression and tensile tests were conducted at temperatures ranging from room up to $900^{\circ} \mathrm{C}$ and at strain rates ranging from quasi-static to $3500 \mathrm{~s}^{-1}$. In order to conduct these experiments a modified Split Hopkinson Pressure Bar (SHPB) and a direct Split Hopkinson Tension Bar (SHTB) were employed. The elevated temperature dynamic compression tests were conducted using an infrared spot heating source. In order to conduct the elevated temperature uniaxial tensile tests, an induction coil heating system was employed.

\section{EXPERIMENTAL WORK}

\section{MATERIAL}

Gamma Met PX has a chemical composition of Ti-45Al-X(Nb, B, C). The material used in the present study was supplied by Plansee AG in the form of $12.5 \mathrm{~mm}$ rods. The material was VAR cast and then hot extruded above the alpha transus temperature. The extrusion ratio was 100:1 and the bars are in the as-extruded condition. Microstructural investigation, Figure 1, shows that the material consists of nearly lamellar microstructure. The nearly lamellar microstructure has been shown to provide these alloys with high strength and acceptable levels of ductility (Kim, 1989). 


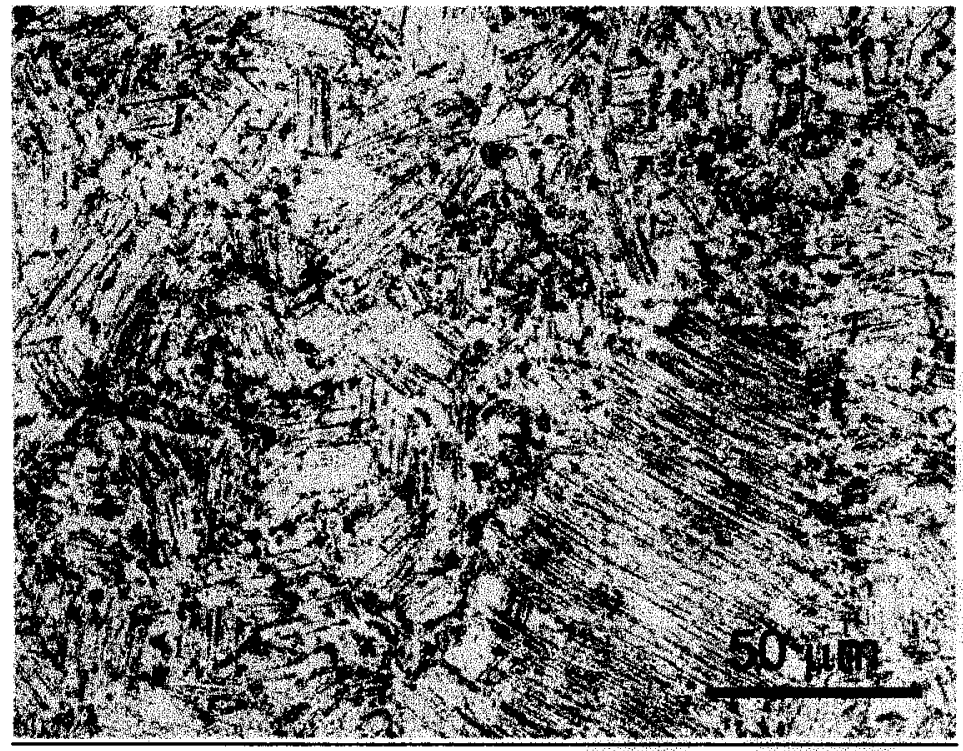

Figure 1: Microstructure of the as received Gamma Met PX

\section{QUASI-STATIC COMPRESSION TESTS AT ROOM AND ELEVATED TEMPERATURES}

In order to conduct the quasi-static compression tests, cylindrical test specimens, $4 \mathrm{~mm}$ in diameter and $8 \mathrm{~mm}$ long, were prepared by electro-discharge machining parallel to the extrusion direction from as-extruded bars of Gamma Met PX. Using these specimens constant strain rate compression testing was performed from room temperature to $870{ }^{\circ} \mathrm{C}$ in air at engineering strain rates of $1 \times 10^{-4} \mathrm{~s}^{-1}$. Testing was terminated at $2270 \mathrm{kgf}$ for the $23{ }^{\circ} \mathrm{C}$ to $650^{\circ} \mathrm{C}$ tests and at $30 \%$ strain for the $760^{\circ} \mathrm{C}$ to $870^{\circ} \mathrm{C}$ tests.

\section{DYNAMIC COMPRESSION TESTS AT ROOM AND ELEVATED TEMPERAURES}

A Split Hopkinson Pressure Bar (SHPB) is employed to conduct the room and elevated temperature high strain rate compression tests. The development and analysis of the SHPB can be found elsewhere (Follansbee, 1985; Gray, 2000). The SHPB facility at CWRU is shown in Figure 2, and comprises a striker, incident and a transmitter bar made from $19.05 \mathrm{~mm}$ diameter high strength maraging steel and having nominal yield strength of $2500 \mathrm{MPa}$. The striker bar is approximately $0.508 \mathrm{~m}$ long, while the incident and transmitted bars are $1.524 \mathrm{~m}$ long. The striker bar is accelerated using an air operated gas gun. A pair of strain gages (Measurements Group WK-06-250BF-10C) are strategically attached on each of the incident and transmitted bars and are used in combination with a Wheatstone bridge circuit connected with a differential 
amplifier (Tektronix 5A22N) and a digital oscilloscope (Tektronix TDS 420) to monitor the strain during the test. The impact velocity of the striker bar was varied from 7 to $15 \mathrm{~m} / \mathrm{sec}$ so as to obtain strain rates in the range $1200 \mathrm{~s}^{-1}$ to $3500 \mathrm{~s}^{-1}$.

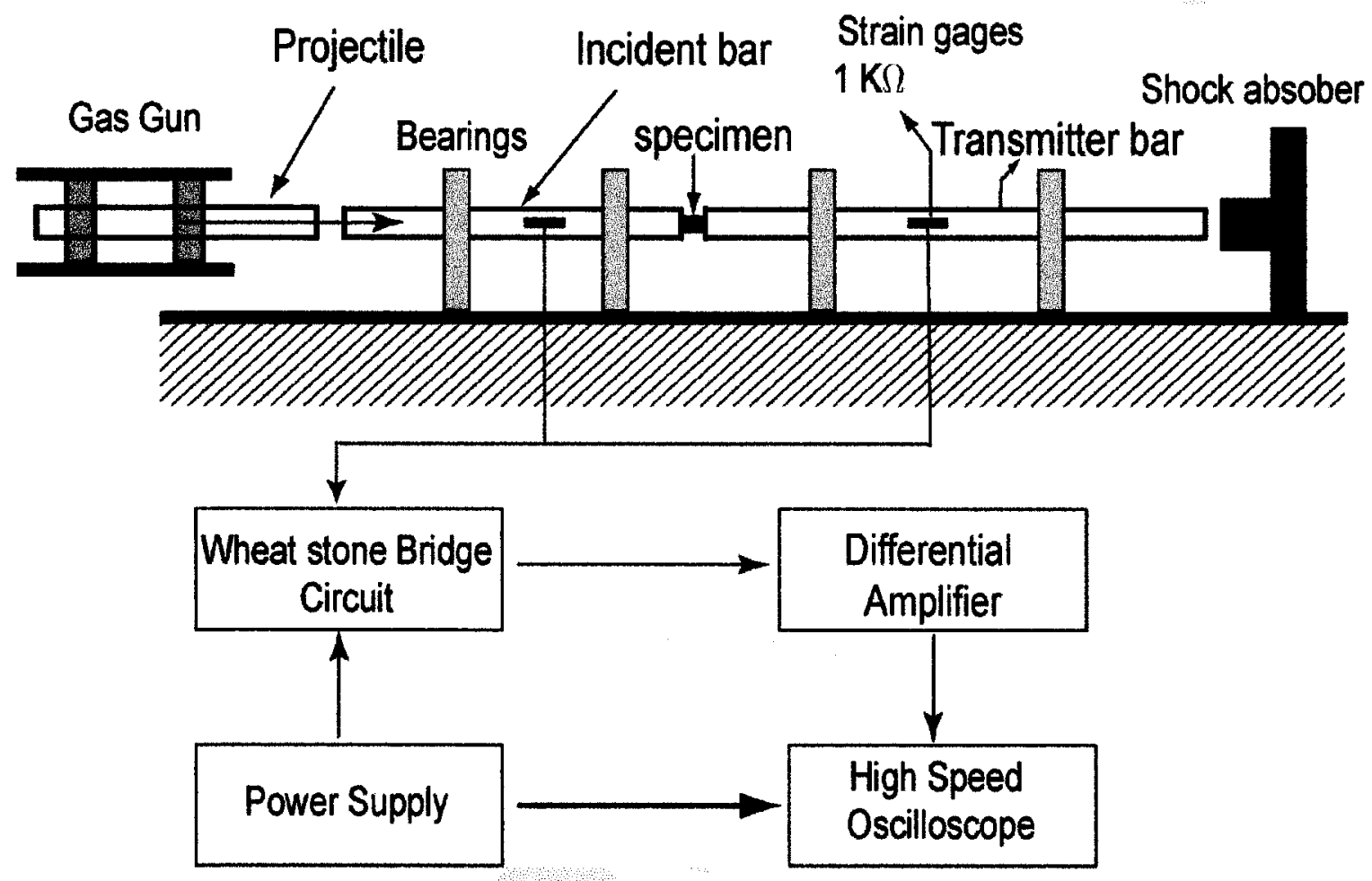

Figure 2: Schematic of Split-Hopkinson Bar used to conduct the dynamic compression tests.

For the determination of dynamic flow characteristics of Gamma Met PX, cylindrical compression tabs (4.70 $\mathrm{mm}$ diameter by $2.35 \mathrm{~mm}$ thick) were machined from a $12.7 \mathrm{~mm}$ diameter bar. The relatively small size of the specimens allow a stress amplification (ratio of stress in the sample to stress in bar) of 16:1, which was found to be necessary to deform the specimens at high strain rates in view of the high yield-stress of Gamma Met PX alloy. Prior to the tests the two lateral surfaces (faces) of the specimens were ground and lapped flat. For the room temperature experiments molybdenum grease is applied liberally in order to minimize friction at the specimen/bar interface. 
Determination of dynamic response of a material at elevated temperatures using the SHPB is a challenging task. This is primarily due to the fact that heating the specimen, while in contact with the bars, results in heating the ends of the incident and transmitter bars. This leads to a temperature gradient in the two bars, which in turn affects their elastic modulus and density, both of which are known to vary with temperature. Thus, in order to obtain accurate stress-strain curves, a correction needs to be applied to the strain-gage signals to compensate for the temperature dependent longitudinal wave velocity and elastic modulus by estimating the temperature gradient in the bars. One way to solve this problem is to heat the specimen alone to the desired test temperature and then bring the cold bars to contact with the specimen. However, the problem encountered with this procedure is the cold contact time. As soon as the bars come in contact with the specimen, the specimen loses its temperature by heat conduction to the bars. Figure 3 shows a finite element simulation of heat conduction in the specimen and the bar assembly using the commercial FEM package ABAQUSTM (2001). An initial temperature of $900^{\circ} \mathrm{C}$ is prescribed to the specimen. The analysis shows that a temperature gradient develops within the specimen immediately after the bars are brought in contact.

Several approaches have been used in the past to alleviate these problems. Amongst them an approach based on mechanical devices to bring the bars in contact with the specimen just before the arrival of the pulse at the specimen plane has found wide spread use (see for example, Frantz et al., 1983, and Lennon and Ramesh, 1998). However, synchronization of time for the movement of the bars with the arrival of the loading pulse has remained problematic. Other methods include the use of Inconel 718 bars in testing up to $600^{\circ} \mathrm{C}$, and the use of long aluminum oxide bars in contact with steel bars for testing up to $1500^{\circ} \mathrm{C}$ (Follansbee, 1985). 


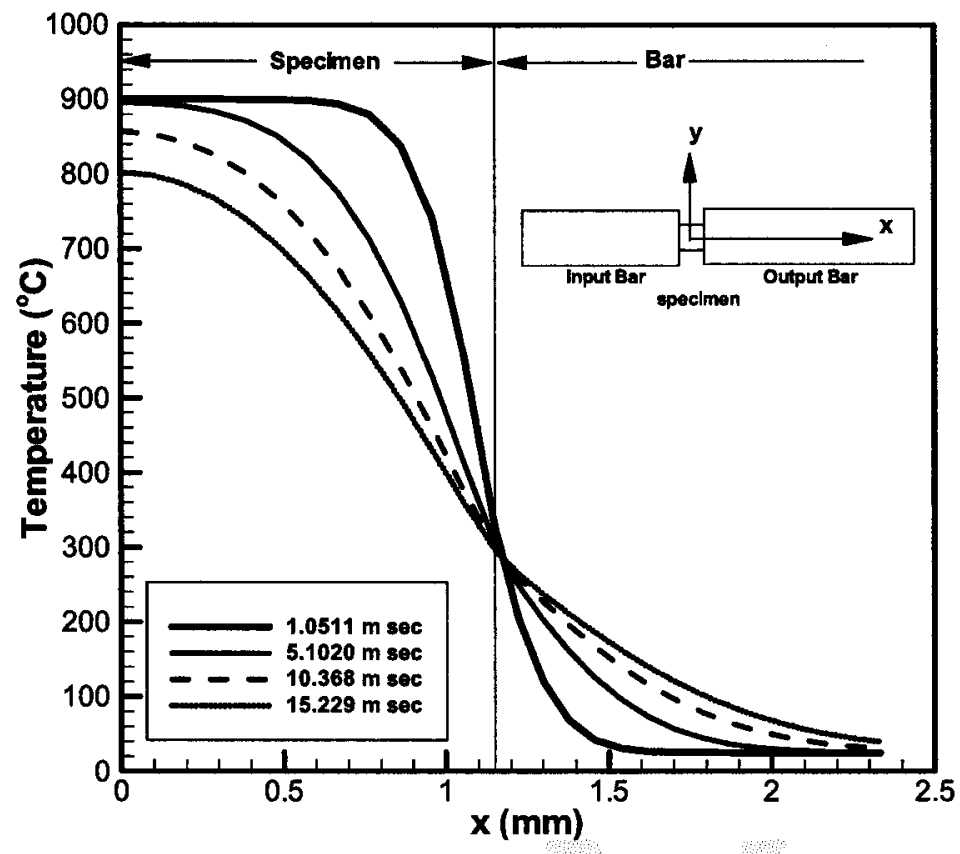

Figure 3: Temperature distribution in the specimen as a function of time after the specimen is brought in contact with the bars.

The schematic layout of the high temperature tests set up at CWRU is shown in Figure 4(a). In addition to the conventional SHPB, two air-cooled infrared spot heaters are used as the heating elements. The IR spot heaters have a circular cut shield which concentrates the heat flux at the focal point ( 0.25 inch diameter) as high as 650 watts per square inch. In order to overcome the problem of cold contact times between the bars and the specimen and thus allow sufficient time for the movement of the bars, the specimen is sandwiched between two WC inserts and the assembly comprising the inserts and the specimen is heated to the desired test temperature. The WC inserts are impedance matched to the incident and the transmitter bars, and hence do not disturb the incident, reflected and the transmitted wave profiles.

Just prior to conducting the test the insert-specimen-insert assembly is heated up to the desired temperature level (usually $50-100^{\circ} \mathrm{C}$ higher than the test temperature). The bars are then brought manually in contact with the assembly. The specimen is held between the two inserts by thermocouple wires pre-deformed to a cup-shape. This allows free radial expansion of the 
specimen during the compression test. The cup-shaped wires are spot welded to a screw that move inside a T-shape copper tube. The T-shape copper tube supports the WC inserts and allows for precise alignment with the incident and transmitter bars, as shown in Figure 4(b). A 0.015 " chromel-alumel wire is spot welded to the specimen to monitor the specimen temperature prior to the test. This allows testing to be carried out over the range from room to $1000^{\circ} \mathrm{C}$. For all the elevated temperature experiments boron nitride was used as the lubricant between the specimen-insert interfaces as well as the insert-bar interfaces.

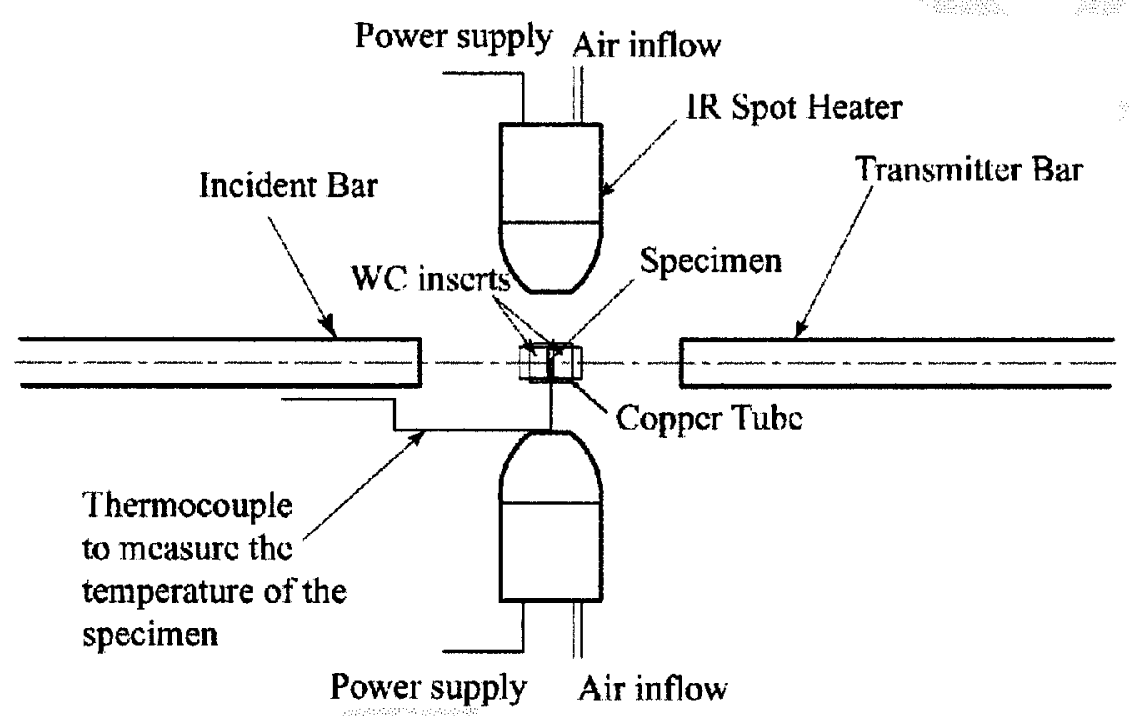

(a)

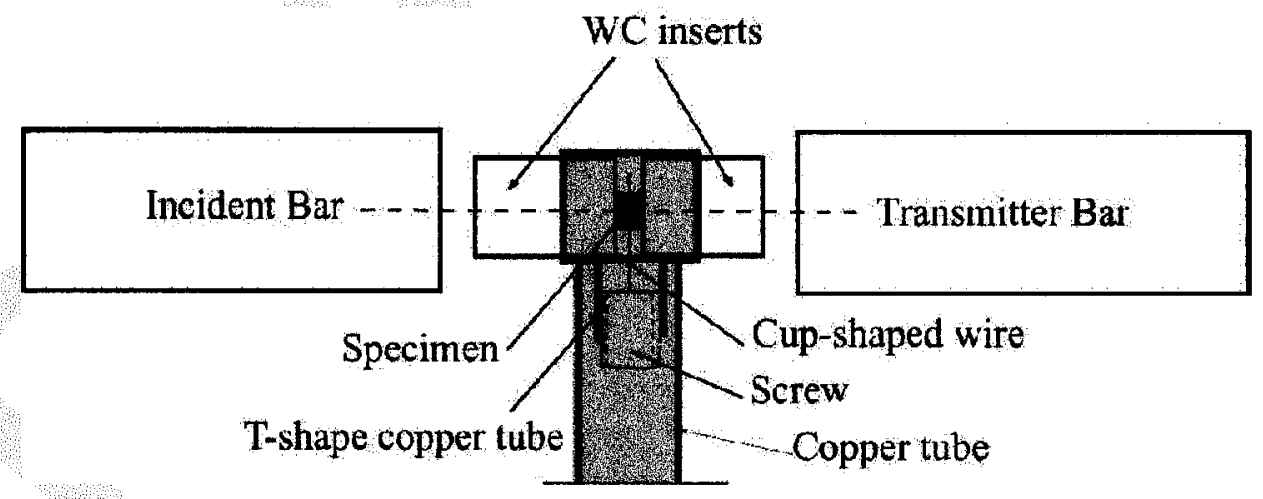

(b)

Figure 4: (a) Schematic layout of the elevated temperature SHPB compression tests. (b): Details of insert-specimen-insert. 
When the bars make contact with the specimen, the WC inserts lose heat to the bars while maintaining the specimen temperature at the desired level for a long enough time-period so as to allow the test to be conducted at nominally uniform temperature conditions within the specimen. A finite element model for the set-up is shown in Figure 5. From the plot we see that for a test to be conducted at $800^{\circ} \mathrm{C}$, an initial temperature of $900^{\circ} \mathrm{C}$ of the specimen and the WC insert assembly allows approximately 6.5 seconds to conduct the experiment before a temperature gradient develops within the specimen. The temperature remains fairly uniform along the entire length of the specimen during this time interval. However, in actual tests, an even longer time to conduct the experiments is available because of the presence of the high temperature lubricant layer between the WC inserts which essentially acts as a thermal barrier, and the fact that the IR spot heaters were left on until just prior to conducting the experiments.

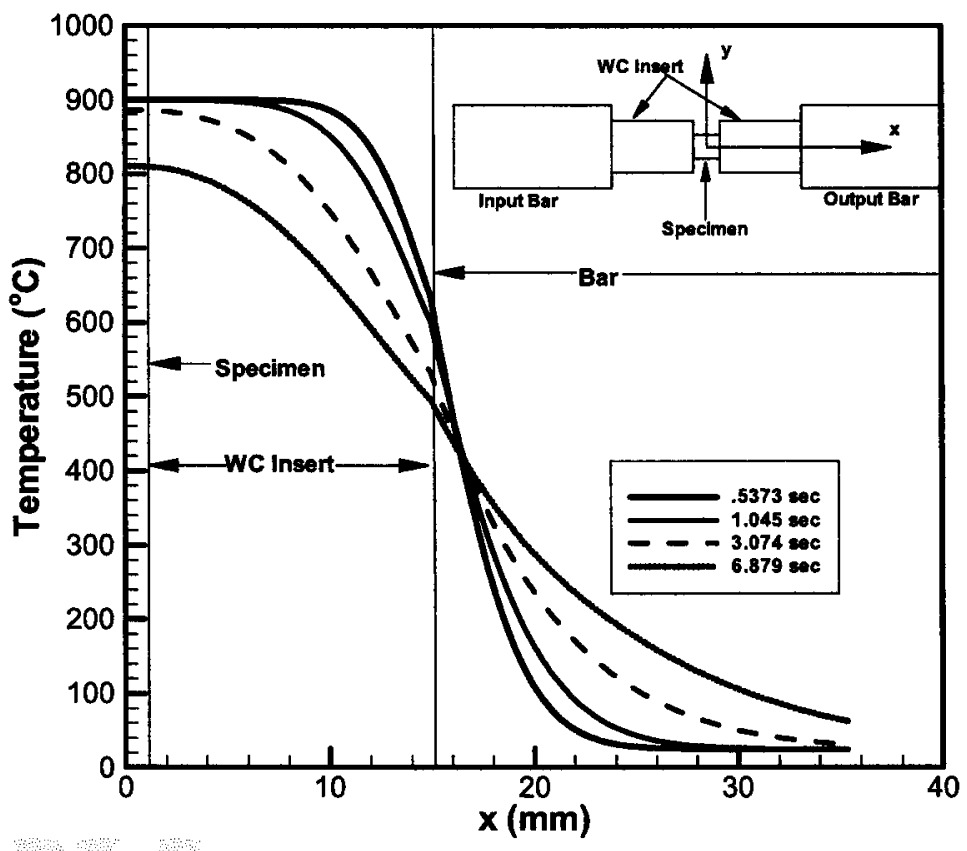

Figure 5: Temperature distribution in the specimen as a function of time. Note the specimen is sandwiched between two WC inserts.

Using this configuration a series of dynamic compression tests was conducted. In this series the impact velocity of the striker bar was varied so as to obtain strain rates from $1000 \mathrm{~s}^{-1}$ to $3500 \mathrm{~s}^{-1}$. 
For all experiments a copper pulse shaper was utilized on the impact end of the incident bar. The pulse shaper aids in dispersing the relatively sharp front of the incident stress wave, thus allowing high-strain-rate experiments to be conducted at near constant strain rates. Also, the slowly rising incident pulse prohibits premature failure of the relatively brittle Gamma-Met PX alloys, especially during the early part of stress wave loading.

\section{QUASI-STATIC TENSILE TESTS AT ROOM AND ELEVATED TEMPERATURES}

Static tensile properties were measured on threaded, miniature dog-bone tensile specimens which were machined by low stress grinding from the extruded bar. The $51 \mathrm{~mm}$ long tensile specimens had a $19 \mathrm{~mm}$ gage length and a $4 \mathrm{~mm}$ diameter and testing was performed in air from 23 to 926 ${ }^{\circ} \mathrm{C}$ using a constant strain rate of $1 \times 10^{-4} \mathrm{~s}^{-1}$. Strain was measured with an axial extensometer attached to the gage section of the specimen.

\section{DYNAMIC TENSILE TESTS AT ROOM AND ELEVATED TEMPERAURES}

Although the method to test materials in tension under high strain rates was introduced a decade after the development of the SHPB (Harding, Wood and Cambell, 1960), the progress in using the Split Hopkinson Tension Bar (SHTB) has been slow due to difficulties inherent in sample design, load application, and data interpretation. The developments, problems and analysis associated with the SHTB can be found elsewhere (Lindholm and Yeakley, 1968; Nemat-Nasser, Issacs and Starrett, 1991; Nicholas and Bless, 1991; Al-Mousawi, Reid and Deans, 1997).

Figure 6 shows a schematic of the layout of the SHTB at CWRU. The SHTB consists of an air operated gas gun, incident bar, transmitted bar, projectile, momentum trap, shock absorber, and strain gage circuits to measure the strain signals on the bars. The gun barrel is a $75 \mathrm{~mm}$ diameter standard pipe and is $1.33 \mathrm{~m}$ in length. It contains a hollow projectile made of hardened 4340 steel with inside diameter of $25.4 \mathrm{~mm}$ outside diameter of $35.9 \mathrm{~mm}$, and a length of $0.609 \mathrm{~m}$. The projectile is equipped with two Teflon pistons, and its inner surface, which rides on the incident

bar, is honed. The incident and transmitted bars are made of hardened 4340 steel with a HRC of 55. The step at the far right end of the incident bar (transfer flange) was built by a welding process using 4340 electrodes, and was machined to the required size prior to heat treatment. The specimens used in the study were solid bars with threaded ends and a tensile gage section, as 
shown in Figure 7. The dimensions of the specimen are similar to those employed successfully in the past for SHTB testing (Nicholas, 1981).

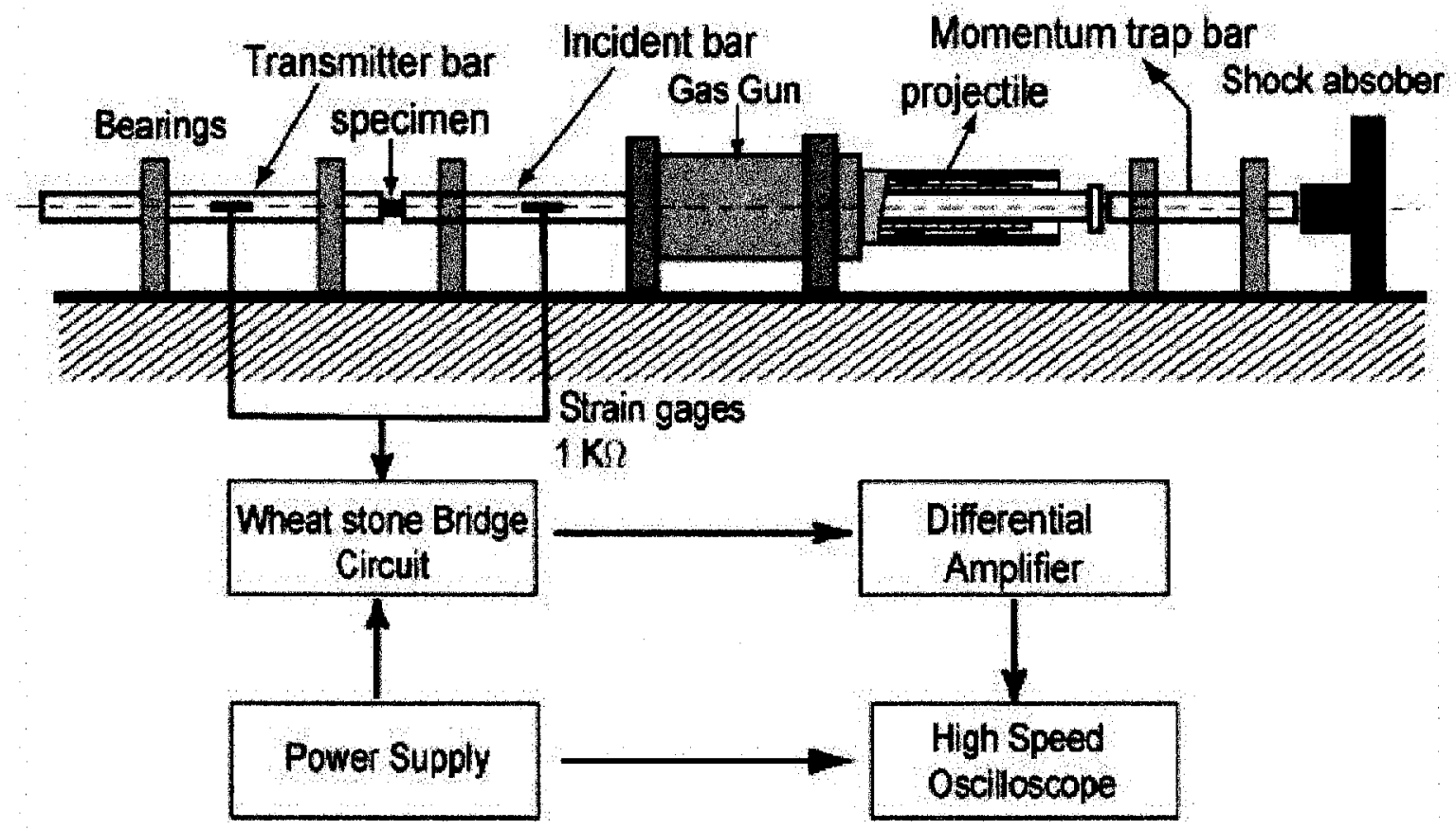

Figure 6: Schematic of Split Hopkinson Tension Bar used in the present investigation. 


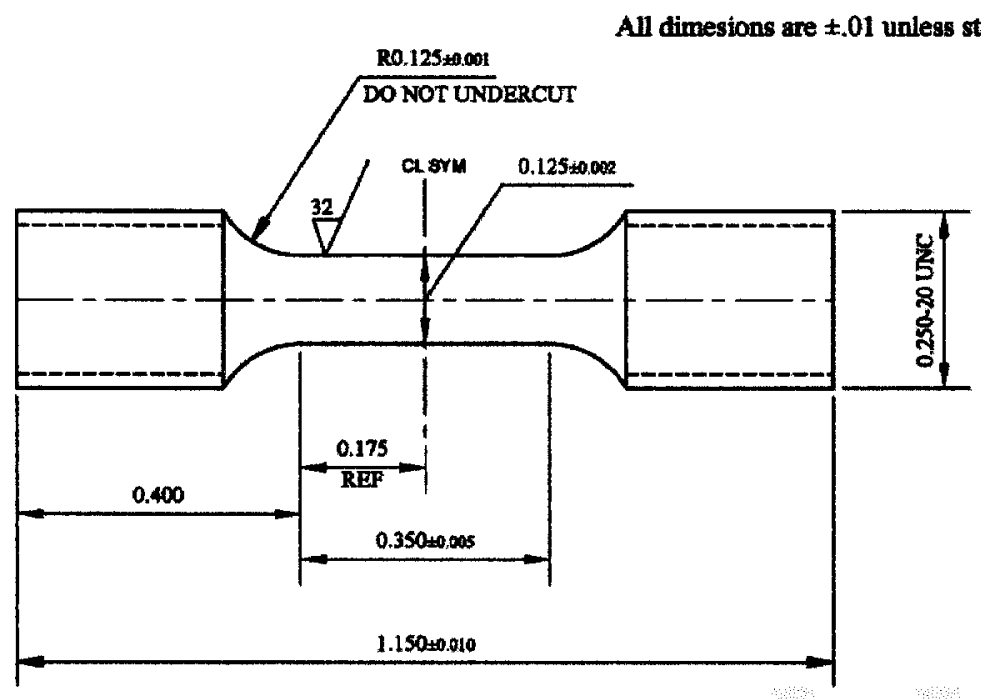

Figure 7: Schematic showing the dimensions of the tensile specimen used in SHTB testing. Please note all dimensions are in inches.

The specimens were machined from Gamma Met PX bars, and a finish grinding operation was performed over the gage length. Prior to conducting the high strain rate experiment, the threaded ends of the specimen were screwed into the input and output metallic bars (these bars are designed to remain elastic during the test). To conduct the experiment the tubular projectile is fired onto the step at the end of the incident bar. A pre-determined gap is kept between the momentum trap bar and the transfer flange such that the end of the momentum trap bar and the face of the transfer flange come in contact once the desired duration of the tensile pulse is transferred to the incident bar through the transfer flange. This tensile pulse then travels towards the specimen, where it is partly transmitted into the transmission bar, and is partly reflected as compression wave back into the incident bar. In the experiments the impact velocity of the striker bar was varied from 4 to $8 \mathrm{~m} / \mathrm{s}$ so as to obtain strain rates in the range 500 to $1000 \mathrm{~s}^{-1}$. For all experiments conducted in the present study, a pulse shaper was utilized on the impact end of the incident bar. A pair of foil strain gages (Measurements Group WK-06-250BF-10C) are strategically attached on the incident bar while a pair of semiconductor strain gages (BLH SPB318-100-U1) are attached on the transmitted bar. These gages are used to record the input, reflected, and the transmitted pulses in the bars in combination with a Wheatstone bridge circuit connected with a differential amplifier (Tektronix 5A22N) and a digital oscilloscope (Tektronix 
TDS 420). The magnitudes and timings of the pulses determine the stress and strain rates in the specimen.

With regards to SHTB testing at elevated temperatures, very little previous work exists in the literature (see for example the work by Rosenberg, 1986). In the present investigation, in order to conduct the elevated temperature tests the ends of the incident and transmitted bars were replaced with impedance matched precipitation hardened Inconel 718 inserts (see Figure 8). The Inconel 718 inserts allow extension of the threaded specimen grips to high temperatures and impedance matching helps to avoid wave dispersion that may occur as a result of a change in mechanical impedance at the 4340 steel and Inconel 718 interface. Due to the relatively large diameter of the SHTB bar $(25.4 \mathrm{~mm})$ to that of the SHPB $(19.05 \mathrm{~mm})$, it was not possible to get the specimen surface at the focal point of the infra-red spot heaters used in the SHPB elevated temperature experiments. Instead, the specimens were heated using induction heating technique by using a water cooled Hüttinger TIG 10/100 RF generator. This generator uses 3-phase 230-V power line and delivers a maximum power of $10 \mathrm{~kW}$ at $100 \mathrm{kHz}$. The power is coupled to the specimen by using 0.125 " copper tubing coils. In the present study, a coil of $12 \mathrm{~mm}$ inside diameter and $9 \mathrm{~mm}$ long (two round turns) was used. To avoid damage by coil current to the semiconductor strain gages (attached to the transmitted bar), the coil was insulated from the bars by using ceramic inserts. The temperature of the specimen was monitored by 0.015 " diameter chromel-alumel thermocouple wires placed against the specimen surface. Spot welding of the thermocouple wire was not performed to avoid damaging the specimen surface that may lead to premature failure of the specimen in the spot welded region.

Prior to experiment, the specimen gage section was heated up to a temperature higher than the test temperature (usually $50-100^{\circ} \mathrm{C}$ above the desired test temperature). The induction coil heating system was then shut off allowing the temperature to fall. The temperature was then monitored until it dropped to 5 to $10^{\circ} \mathrm{C}$ above the desired test temperature, then the projectile was fired and the test is performed. The relatively small diameter of the gage section, the high heating capacity of the induction heating system, and the extension of the heating coil turns along the gage section assure the localization of heat in the gage section. However, due to the 
stability of this alloy ( $\alpha$-transus higher than $1200^{\circ} \mathrm{C}$ ), high heating rate is not expected to change the microstructure in the range of test temperature.

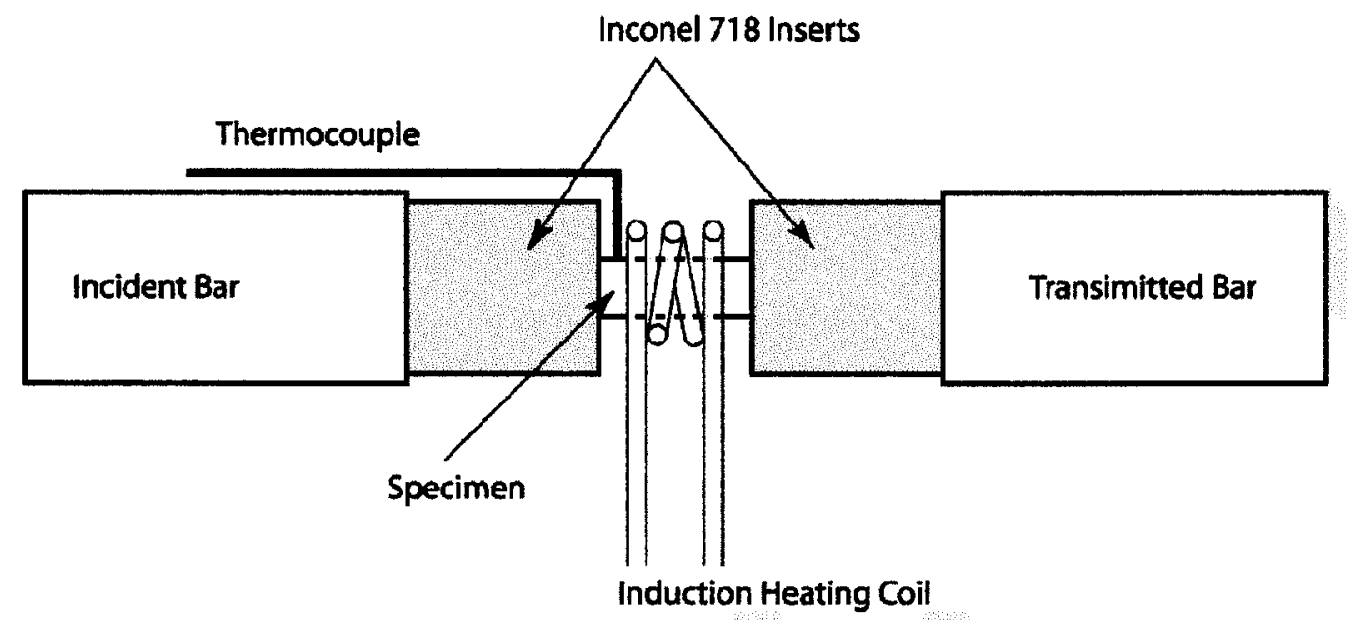

Figure 8: SHTB high temperature set-up used in the present investigation.

\section{RESULTS AND DISCUSSIONS}

\section{COMPRESSION TESTING OF GAMMA MET PX}

Figure 9 shows the stress versus strain curves obtained under uniaxial compression at a strain rate of $10^{-4} \mathrm{~s}^{-1}$. The test temperature in these tests range from room to $870^{\circ} \mathrm{C}$. Figure 10 shows the effect of test temperature on the $0.2 \%$ yield strength as well as the flow strength at a total strain of $10 \%$. At room temperature the yield strength of the material is $1100 \mathrm{MPa}$. Both the yield and flow strength fall rapidly as the test temperature is increased beyond $650^{\circ} \mathrm{C}$; the yield strength drops to one-half of its room temperature level as the test temperatures approach $870^{\circ} \mathrm{C}$. Moreover, at test temperatures of $760^{\circ} \mathrm{C}$ and beyond, compressive strains of $30 \%$ are observed prior to failure. The material shows strain hardening at all levels of plastic strain up to test temperatures of $760^{\circ} \mathrm{C}$. At temperatures between $815^{\circ} \mathrm{C}$ and $870^{\circ} \mathrm{C}$, after some initial strain hardening, the material shows rapid strain softening at all levels of plastic strain. This behavior is similar to the behavior of Ti-25Al-10Nb-3V-1Mo observed at a strain rate of $10^{-3} \mathrm{~s}^{-1}$ and test temperatures of $1000^{\circ} \mathrm{C}$ (Vaidya et al., 1999). No yield anomaly is observed up to $870^{\circ} \mathrm{C}$. This behavior is in agreement with results for $\mathrm{Ti}-46.5 \mathrm{Al}-2 \mathrm{Cr}-3 \mathrm{Nb}-0.2 \mathrm{~W}$ (Jin et al., 1997) and Ti- 
48Al-2Cr-2Nb (Maloy and Gray III, 1996), and contrary to the results for Ti-48Al-2Cr, and Ti47.5Al-1Cr, both of which show a yield anomaly at $200^{\circ} \mathrm{C}$ (Morris, 1994; Bartels et al., 1995).

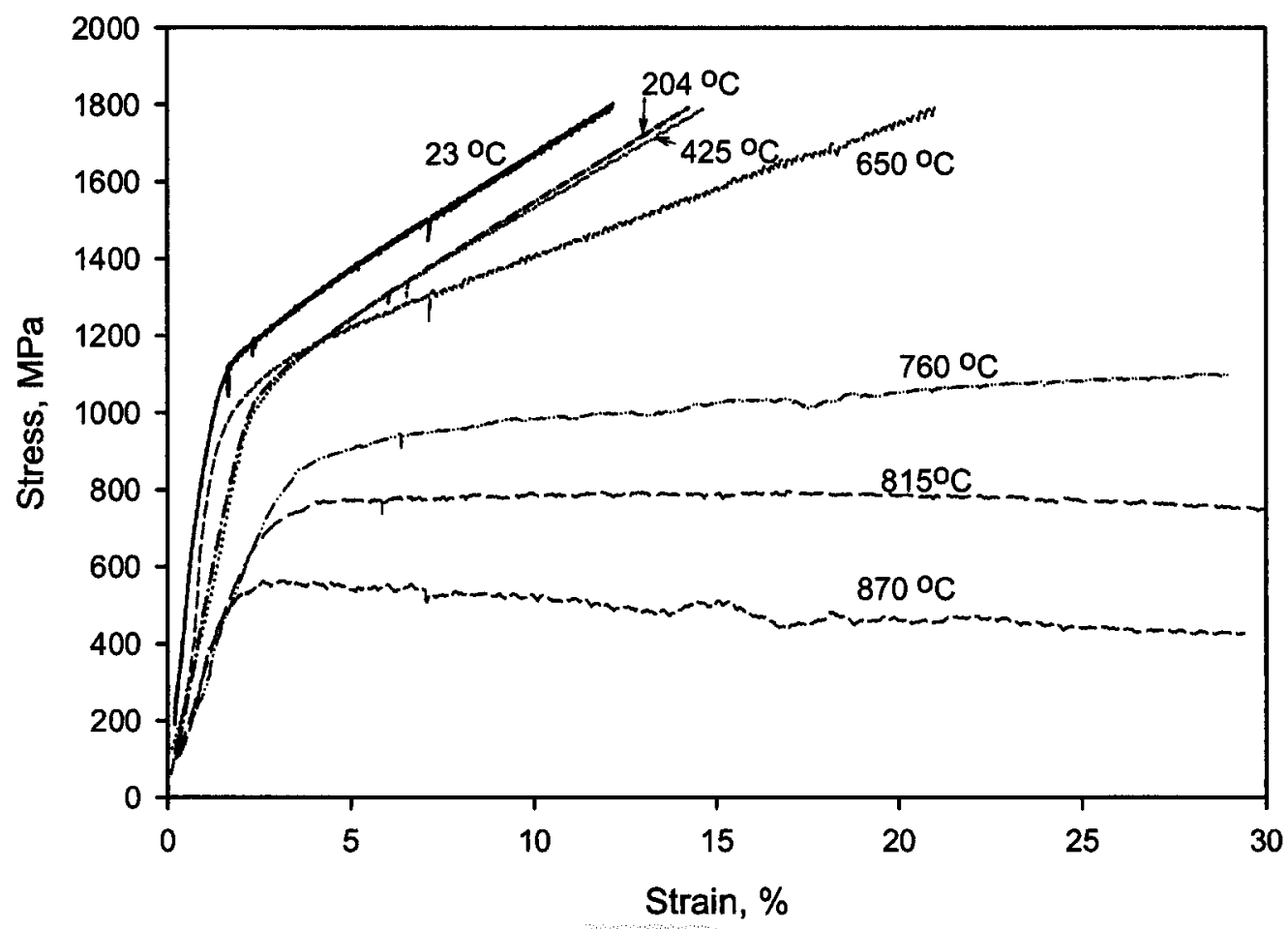

Figure 9: Quasi-static compressive response of Gamma Met PX at elevated temperature 


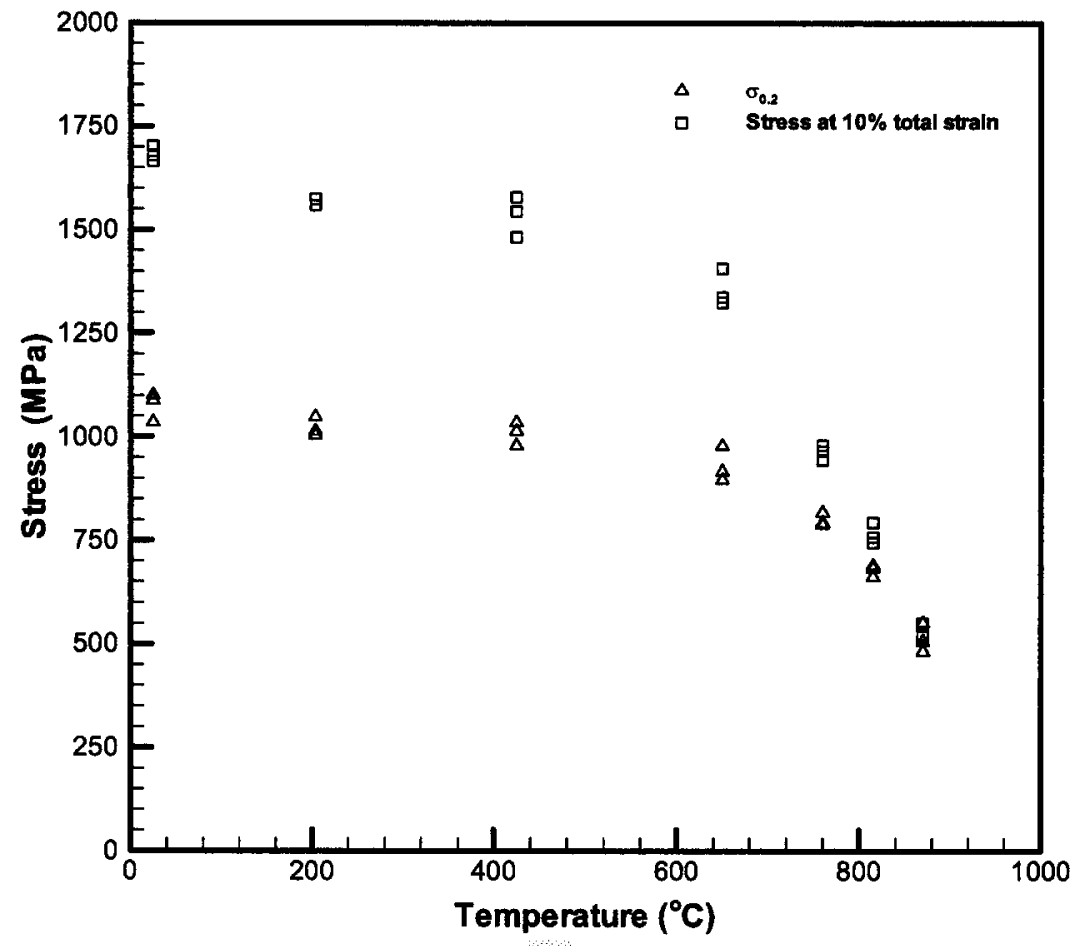

Figure 10: Effect of test temperature on .2\% compression yield strength and the stress at $10 \%$ total strain of Gamma-Met PX.

Figure 11 shows typical incident, transmitted and the reflected strain profiles from a typical low impact velocity SHPB experiment conducted at room temperature by utilizing a copper pulse shaper. The relatively long rise-time in the incident pulse is a consequence of the copper pulse shaper. The reflected pulse indicates that a constant strain rate is achieved during the experiment. In all experiments strain gage amplifiers with a dynamic bandwidth of DC to $1.0 \mathrm{MHz}$ were employed. However, in the data post processing step, a low pass filter was used to filter off the high frequency noise from the data. 


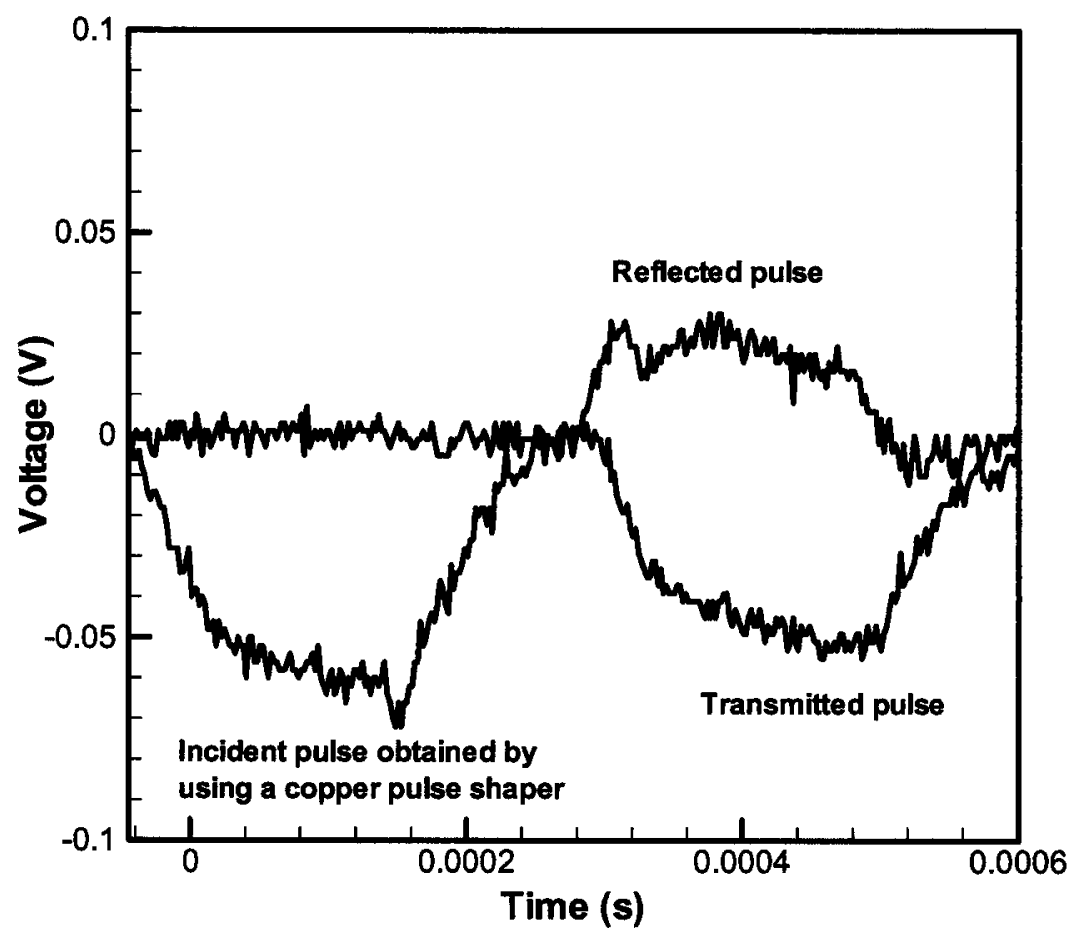

Figure 11: Typical incident, reflected and transmitted strain profiles obtained from a high strainrate SHPB experiment.

Figure 12 shows typical room temperature dynamic compression tests on Gamma Met PX as a function of strain rate. Due to the relatively brittle nature of these alloys true strains of only 0.3 were obtained during the experiments. It is interesting to note the relatively strong strain-rate sensitivity of the alloy at all levels of plastic strain as the strain rate is increased from $0.01 \mathrm{~s}^{-1}$ to $3500 \mathrm{~s}^{-1}$. The yield stress of the alloy is approximately $1250 \mathrm{MPa}$ at a strain rate of $0.01 \mathrm{~s}^{-1}$ and increases to $2250 \mathrm{MPa}$ at a strain rate of $3500 \mathrm{~s}^{-1}$. Also, the alloy shows strain hardening at all levels of strain rates employed in the tests. The test conducted at $3500 \mathrm{~s}^{-1}$ resulted in complete failure of the specimen in the form of small fragments. In all the other tests, dynamic compression is stable and does not lead to fragmentation of the specimen. 


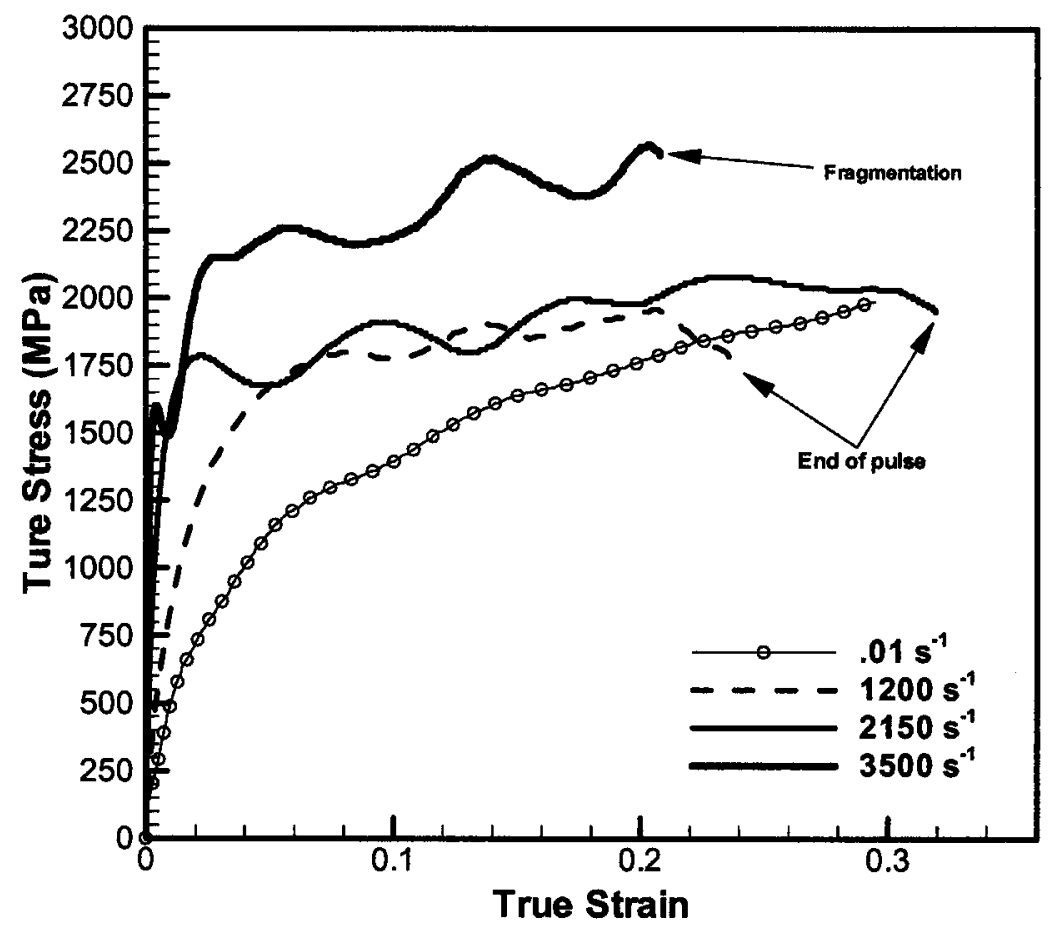

Figure 12: Dynamic compressive response of Gamma Met PX at room temperature as a function of strain rate.

Figure 13 shows the dynamic response of Gamma Met PX obtained by using the high temperature SHPB facility at CWRU. The dynamic behavior is shown at nominal strain rates of 1800 to $2150 \mathrm{~s}^{-1}$ and temperatures ranging from room to $900^{\circ} \mathrm{C}$. From the figure it can be seen that the change in flow stress with temperature is negligible between room temperature and $400^{\circ} \mathrm{C}$. At test temperatures between $600^{\circ} \mathrm{C}$ and $800^{\circ} \mathrm{C}$ the flow stress shows some low levels of thermal softening. However, between $800^{\circ} \mathrm{C}$ and $900^{\circ} \mathrm{C}$ the thermal softening is observed to increase appreciably, resulting in a large drop in flow stress. However, the measured level of flow stress at $900^{\circ} \mathrm{C}$ is still higher than those measured for other gamma alloys at a temperature range (Jin et al., 1995; Maloy and Gray, 1996; Gardiner et al., 1997; Bartels et al., 2002) to be noted that although the flow-stress shows thermal softening with increasing temperature the strain hardening changes very little over the entire range of test temperatures. This is contrary to what has been reported for Ti-48-2-2 with duplex microstructures (Gardiner et al., 1997), where 
the strain hardening rate increases with increasing strain rate, and remains essentially constant over the entire temperature range.

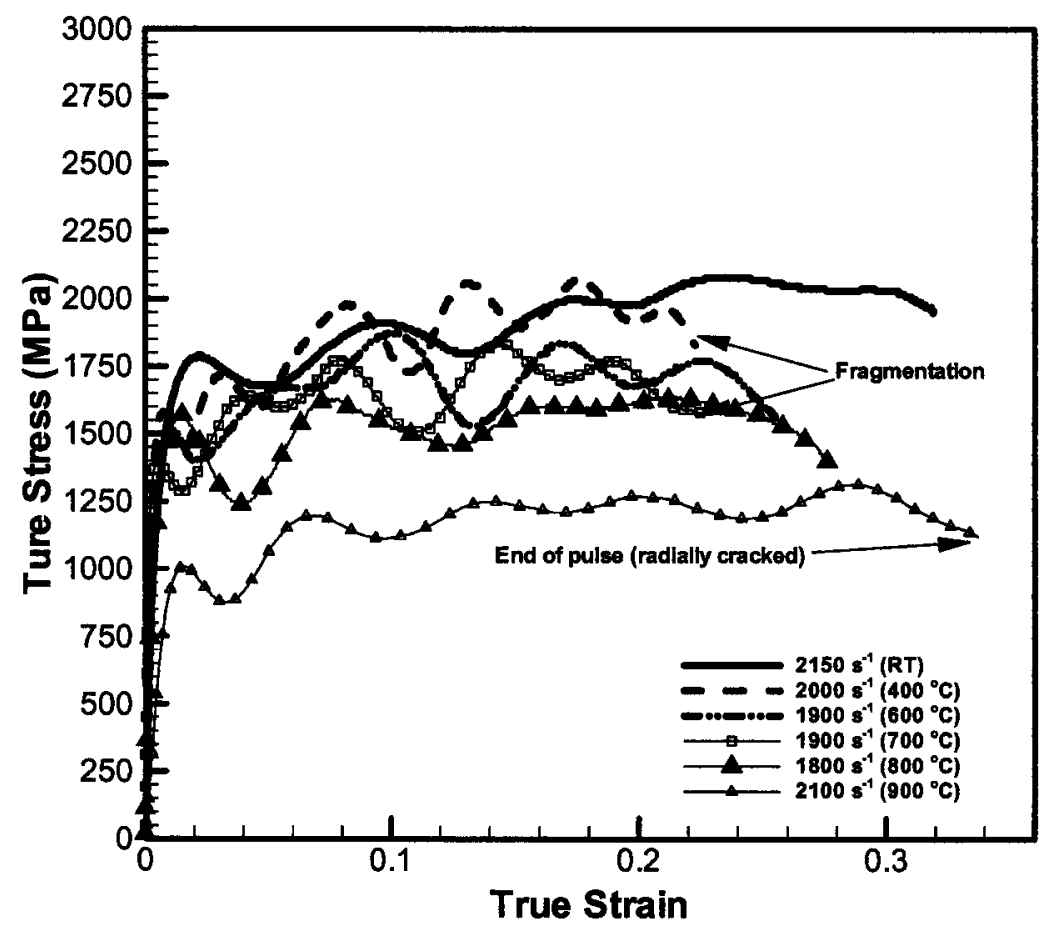

Figure 13: Dynamic compressive response of Gamma Met PX at strain rates of 1800 to $2150 \mathrm{~s}^{-1}$ and temperatures ranging from room to $900^{\circ} \mathrm{C}$.

Figure 14 shows the dynamic response of Gamma Met PX at nominal strain rates of $3000 \mathrm{~s}^{-1}$ to $3500 \mathrm{~s}^{-1}$ and at temperatures ranging from room to $900^{\circ} \mathrm{C}$. At these high-strain-rates the flow stress is observed to be consistently higher than those measured at approximately $2000 \mathrm{~s}^{-1}$. Moreover, during the experiments complete fragmentation of the specimen is observed at room, $700^{\circ} \mathrm{C}$, and $800^{\circ} \mathrm{C}$ test temperatures. However, the specimen tested at $900^{\circ} \mathrm{C}$ shows better ductility and does not result in complete fragmentation. Instead, radial cracking of the specimen is observed. Unlike other Gamma alloys with similar aluminum content which show yield anomaly at $600^{\circ} \mathrm{C}$ (Jin et al., 1995; Maloy and Gray, 1996), Gamma Met PX alloy does not show any yield anomaly up to test temperatures of $900^{\circ} \mathrm{C}$. Also, the ductility of Gamma Met PX is higher than other gamma based TiAl alloys, especially at test temperatures beyond $800^{\circ} \mathrm{C}$. 


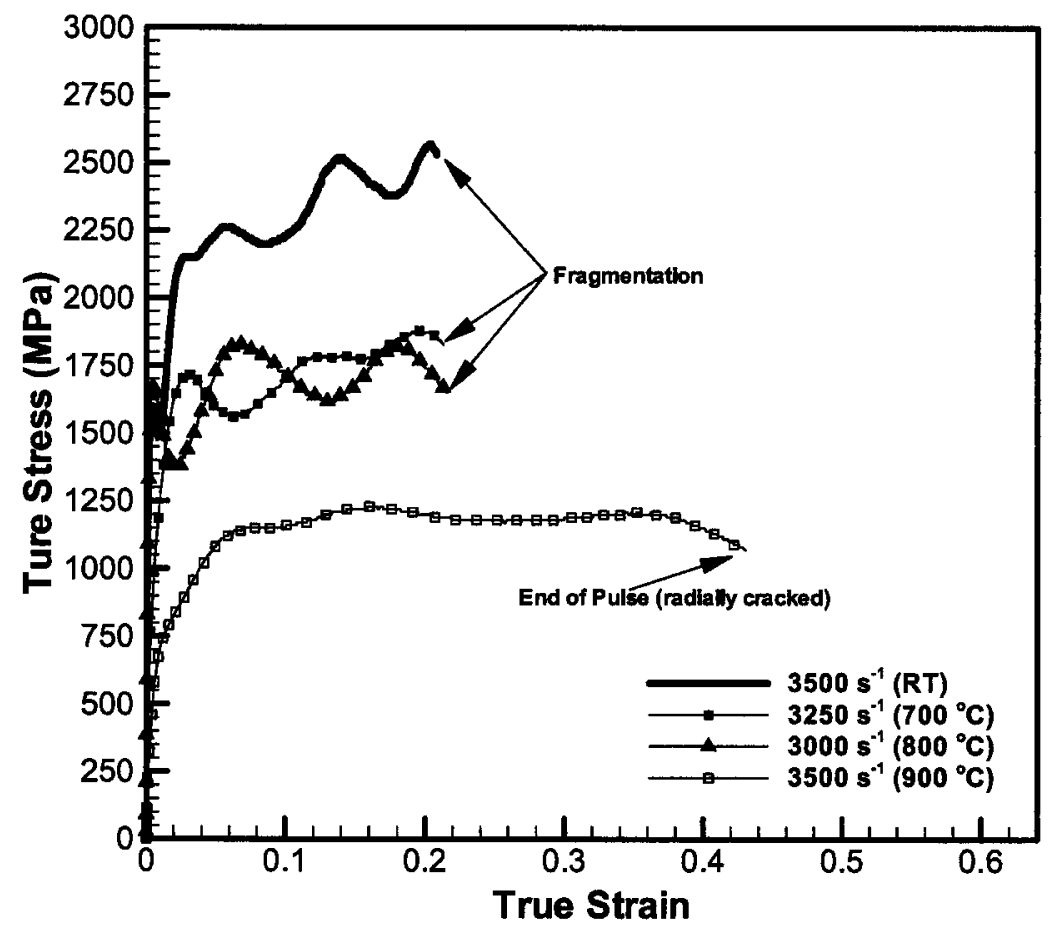

Figure 14: Dynamic compressive response of Gamma Met PX at strain rates of 3000 to $3500 \mathrm{~s}^{-1}$ and temperatures ranging from room to $900^{\circ} \mathrm{C}$.

\section{TENSILE TESTING OF GAMMA MET PX}

Quasi static experiments were conducted at test temperatures ranging from room to $926^{\circ} \mathrm{C}$. At room temperature, Gamma Met PX has yield strength of $1100 \mathrm{MPa}$ in tension with a total strain to failure of $2.13 \%$. Figure 15 shows the corresponding stress versus strain curves obtained under uniaxial tension. Figure 16 shows the effect of test temperature on the $0.2 \%$ yield strength and the ultimate tensile strength (UTS). A negligible effect of temperature is observed up to $600^{\circ} \mathrm{C}$. Above $600^{\circ} \mathrm{C}$, however, both are observed to drop significantly. The $0.2 \%$ yield strength drops to almost one third of its room temperature value at $926^{\circ} \mathrm{C}$. 


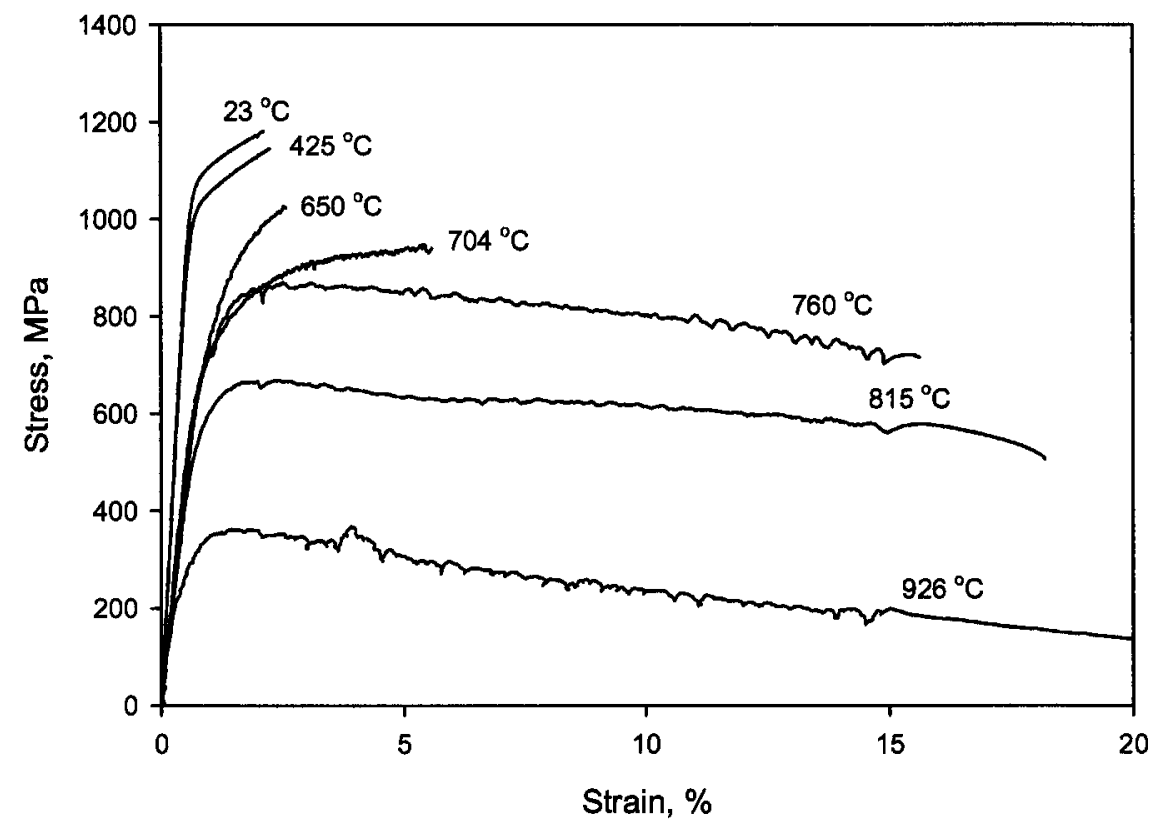

Figure 15: Quasi-static tensile response of Gamma Met PX at elevated temperature

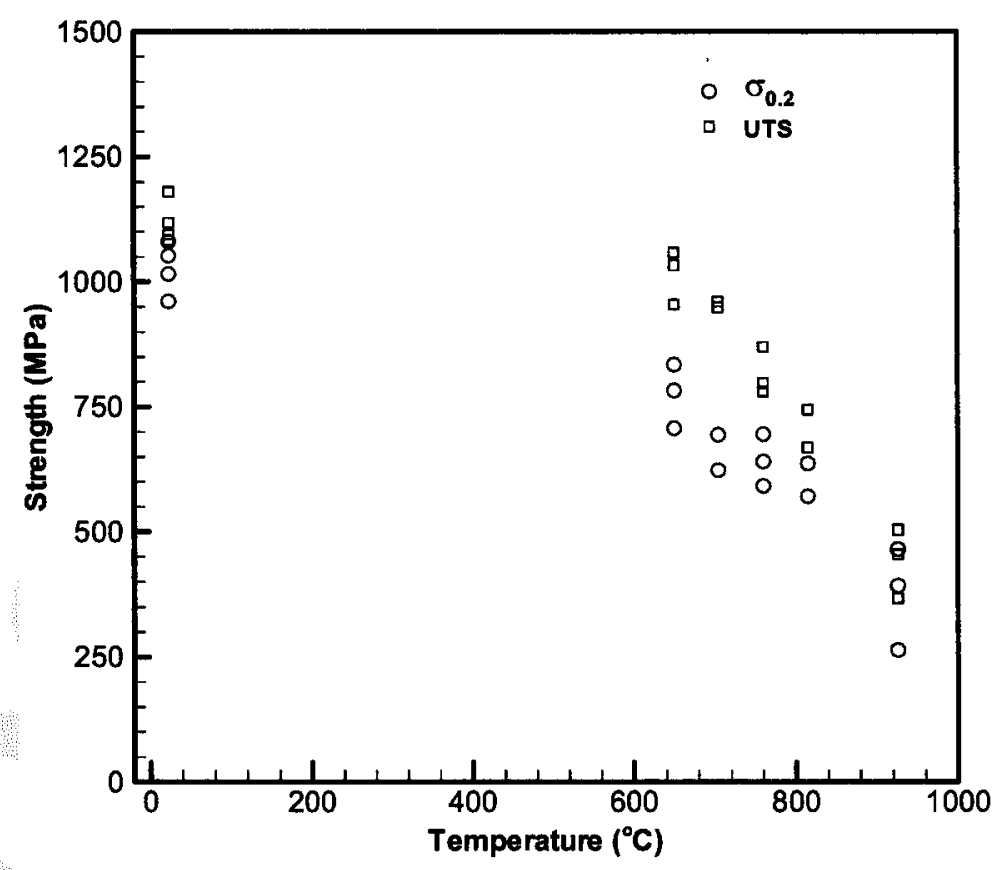

Figure 16: Effect of test temperature on .2\% tensile yield strength and UTS of Gamma-Met PX. 
Figure 17 shows the effect of test temperature on plastic strain and the total strain to failure. It is interesting to note that the ductility of gamma Met PX increases as the test temperature is increased beyond $600^{\circ} \mathrm{C}$. At a temperature of $926^{\circ} \mathrm{C}$ the measured average ductility is as high as $23 \%$. These results confirm that gamma Met PX shows superior strength at room and elevated test temperature when compared with conventional gamma titanium alloys tested under similar conditions (Kumpfert, Kim and Dimiduk, 1995; Wang et al., 1999a; Das and Clemens, 1999; Wang et al., 2000).

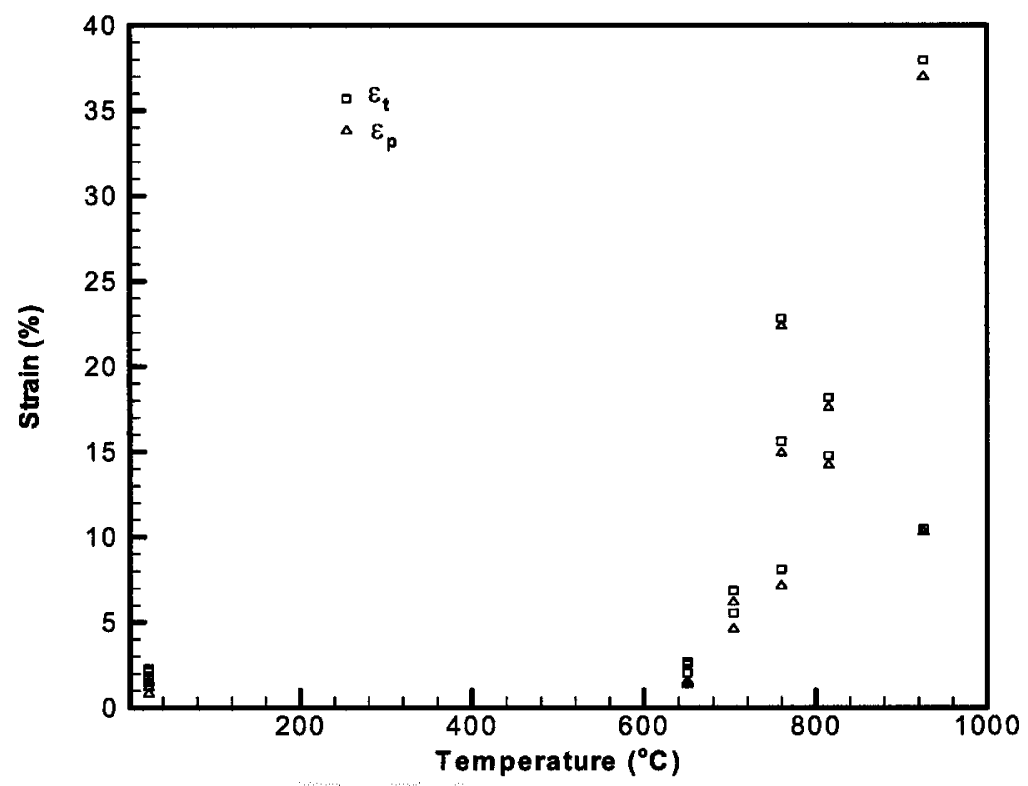

Figure 17: Effect of test temperature on the tensile plastic and total stains to failure of GammaMet PX.

Figure 18 shows the incident, transmitted and the reflected strain profiles obtained from a typical low impact velocity SHTB experiment at room temperature. This experiment was conducted by utilizing a wood cork pulse shaper. Due to the high wave speed of this material $(6600 \mathrm{~m} / \mathrm{s})$, the specimen reaches equilibrium within the initial part of the rise time. However, aligning the reflected pulse with transmitted pulse shows that the specimen stays at constant strain rate prior to failure. As in the case of the SHPB, a strain gage amplifier with a bandwidth of $1.0 \mathrm{MHz}$ was used to record the dynamic signals. A low pass filter was used to filter the high frequency noise from the recorded signal. Due to the relatively large weight of the 4340 steel striker (projectile) and the relatively long gage length of the specimen, it was difficult to achieve strain rates higher 
than $1000 \mathrm{~s}^{-1}$. Higher strain rates can be achieved by using a specimen with shorter gage length. However, as pointed out by Staab and Gilat (1991) a shorter gage length may lead to erroneous measurements in strain due to 3-D waves nature of waves generated from the shoulders of the specimen. The results for selected room and elevated temperatures tests are shown in Figure 19. At room temperature, the tensile behavior of the material is observed to be independent of the applied strain-rate in the strain rate range of $200 \mathrm{~s}^{-1}$ to $500 \mathrm{~s}^{-1}$. It should be noted that the strain rates achieved in the dynamic tensile experiments are much lower than those achieved in the SHPB experiments. The primary reason for this is the much larger gage length for specimens used in dynamic tensile testing when compared to those used in dynamic compression testing. Also, due to the limited ductility of gamma met PX, the specimens tend to fail during the rise time of the tensile pulse. As a consequence true stress equilibrium is not achieved in the gage section of the specimen. The strain rates reported in the figure correspond to those inferred at failure of the tensile specimens.

When compared with $\mathrm{Ti}-47 \mathrm{Al}-1.5 \mathrm{Cr}-.5 \mathrm{Mn}-2.8 \mathrm{Nb}$ with duplex and fully lamellar microstructures (Wang et al., 1999b) and with Ti-47Al-2Mn-2Nb with nearly lamellar microstructure (Wang et al., 1999c), Gamma met PX shows higher strength at failure and similar levels of ductility. However, as the test temperatures are increased, Gamma Met PX shows a drop in yield stress as well as flow stress at all levels of plastic strain. Also, the strains to failure are observed to increase with an increase in test temperatures. All specimens were observed to fracture in a brittle manner with the fracture surface remaining essentially normal to the loading direction. 


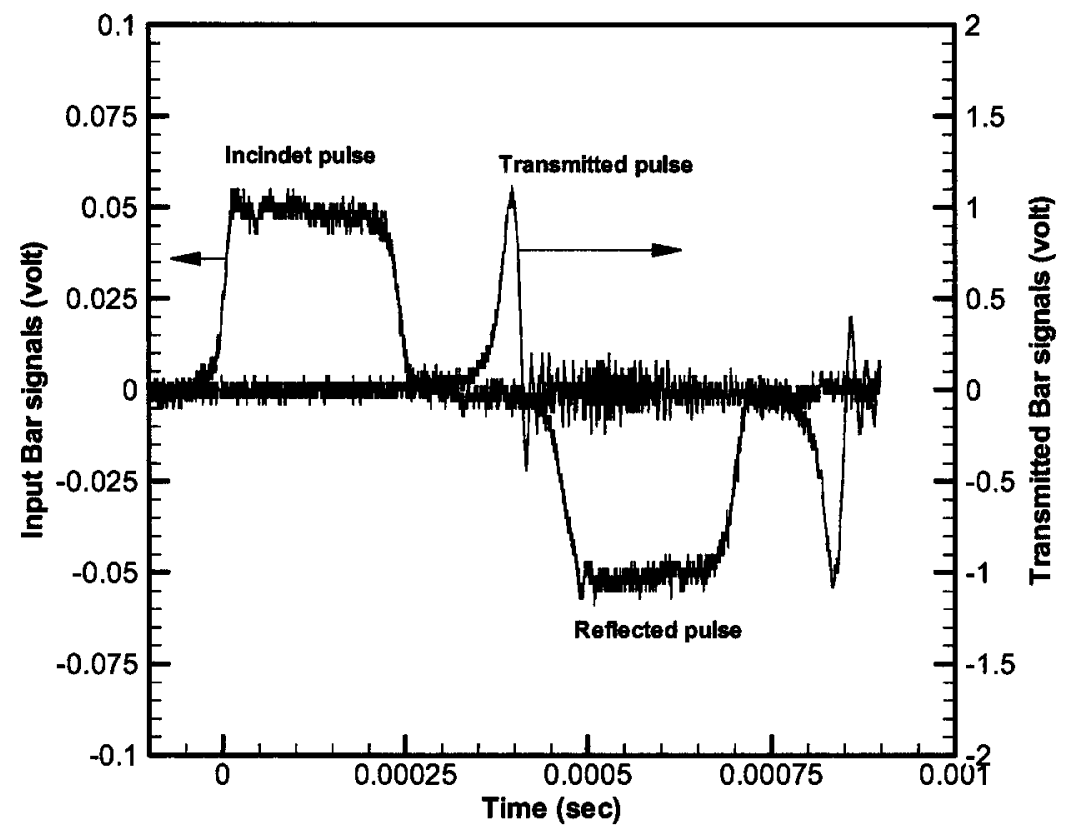

Figure 18: Typical incident, reflected and transmitted strain profiles obtained from a high strainrate SHTB experiment.

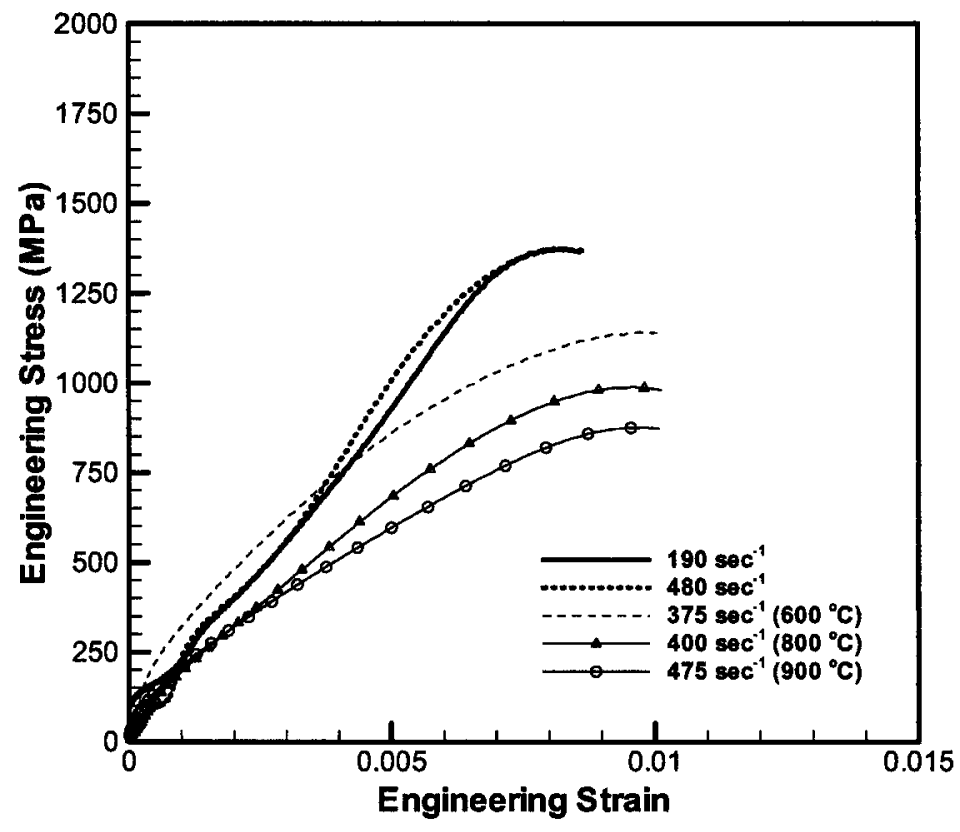

Figure 19: Dynamic tensile response of Gamma Met PX. 
SEM micrographs of the fracture surfaces obtained under the high strain rate tensile loading and elevated temperatures are shown in Figure 20(a) to 20(e). Figure 20(a) shows the fractograph of the specimen tested at room temperature and strain rate of $1000 \mathrm{~s}^{-1}$. A planar cleavage fracture surface consisting primarily of translamellar cracking can clearly be seen. At $600^{\circ} \mathrm{C}$ and similar strain rates (Figure (b)), the fracture morphology changes from translamellar to saw tooth in appearance, presumably due to interlamellar fracture. Some translamellar fracture is also observed in conjunction with interlamellar fracture. At $800^{\circ} \mathrm{C}$ (Figure (c)), both inter colony and interlamellar fracture modes are observed with inter colony being the dominant fracture mode. Also at this temperature, voids at colony boundaries and the pulling out of the $y$-particles start to appear. At $900^{\circ} \mathrm{C}$ (Figure (d)), inter colony fracture is the dominant fracture mode with a larger number of voids appearing on the colony boundaries and the pulling out of the $\gamma$-particles. Figure (e) is a higher magnification of the fracture surface shown in Figure (d), and shows the voids generated at colony boundaries in more detail.

Although the fractographs show a change in fracture mode with increasing test temperature, the effects of the change in mode on ductility is negligible. However, there is a change in the yield stress with increasing test temperatures at the elevated strain rates.

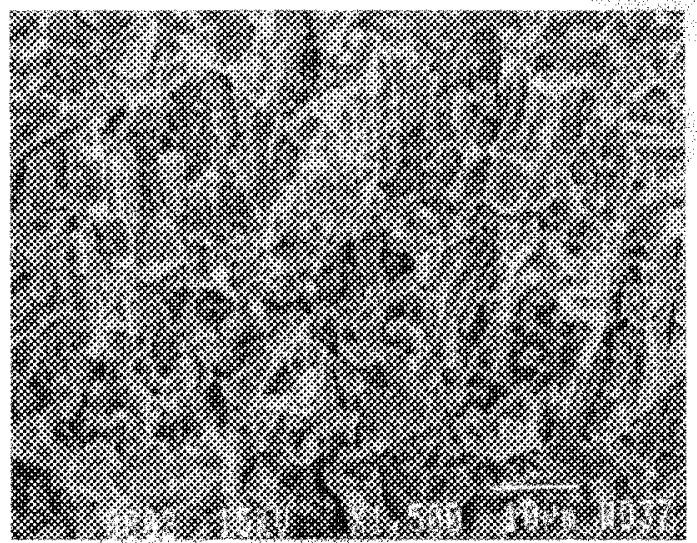

(a)

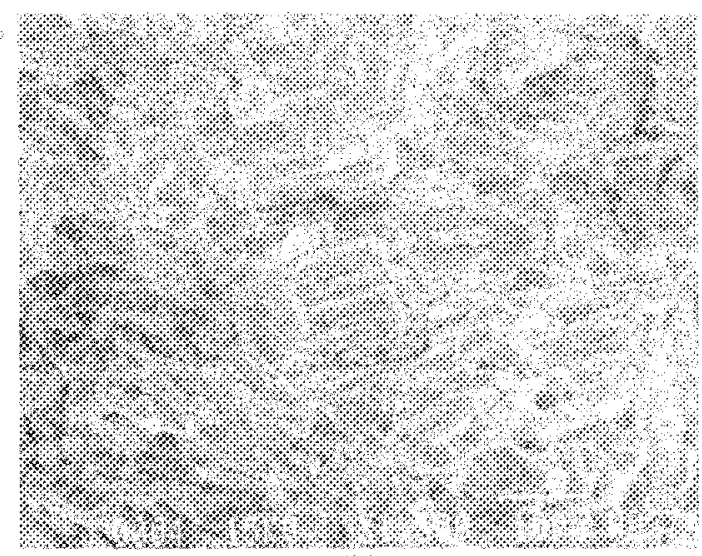

(b) 


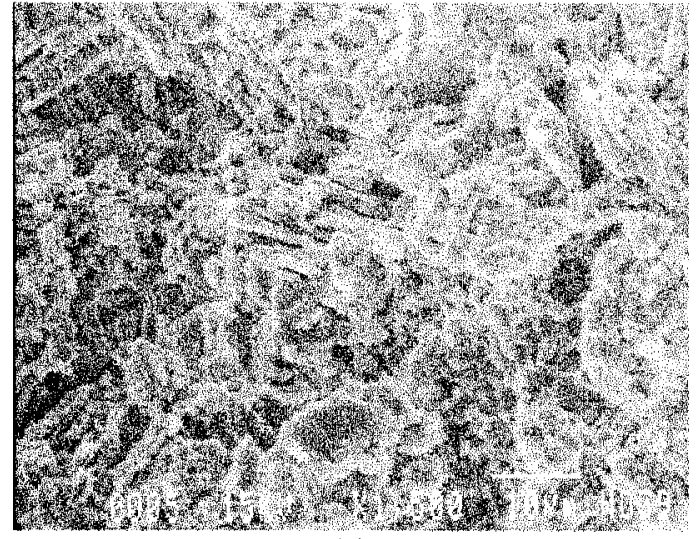

(c)

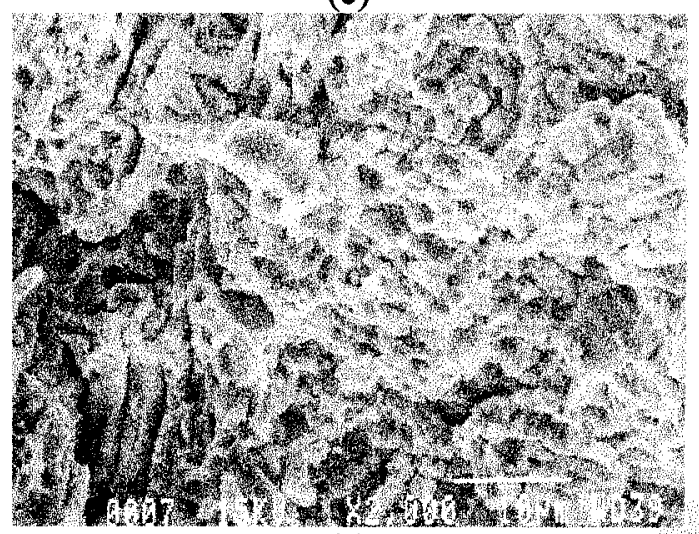

(e)

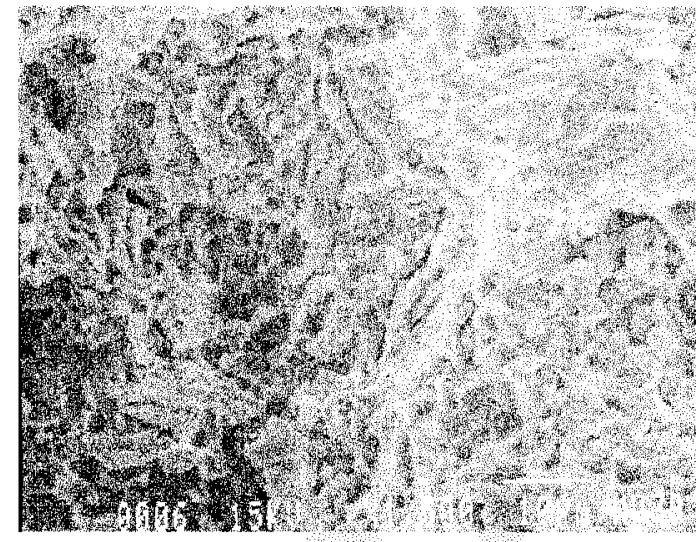

(d)

Figure 20: Fracture surface morphologies at (a) RT, (b) $600^{\circ} \mathrm{C}$, (c) $800^{\circ} \mathrm{C}$, (d) and (e) $900^{\circ} \mathrm{C}$ obtained from the fracture surfaces of the specimens tested under uniaxial tension in the SHTB.

\section{BRITTLE TO DUCTILE TRANSITION TEMPERATURE (BDTT)}

Wang et al. (1999c) and Wang et al. (2000), studied the effect strain rate on the BDTT of gamma titanium alloys. They defined the BDTT as the temperature at which the tensile ductility was equal to $7.5 \%$. Using this definition, they concluded that the BDTT for gamma titanium alloys increases with an increase in applied strain rate. Although their definition had no physical basis, it did support the features observed in the fracture surfaces. Other qualitative definitions of BDTT based on observations of fracture surfaces were used in their work by Huang and Hall (1991) and Kumpfert et al. (1995). However, the general consensus was that any significant change in ductility was linked to BDTT. 
Based on these arguments we can estimate the BDTT for the dynamic compression and dynamic tensile experiments conducted in the present investigation. From the compression tests we can estimate a BDTT of $760^{\circ} \mathrm{C}$ at a strain rate of $10^{-4} \mathrm{~s}^{-1}$, and between $800^{\circ} \mathrm{C}$ and $900^{\circ} \mathrm{C}$ at elevated strain rates. The best estimate for BDTT under tensile loading is between $700^{\circ} \mathrm{C}$ and $800^{\circ} \mathrm{C}$ under quasi-static loading, while no BDTT could be inferred from the results at the elevated strain rates.

The absence of BDTT at elevated strain rates under tensile loading is consistent with the results of Wang et al. (1999a) and Wang et al. (2000). The results of these studies indicate that as the strain rate is increased from $10^{-5}$ to $10^{-1} \mathrm{~s}^{-1}$, BDTT of gamma titanium alloys changes from $750^{\circ} \mathrm{C}$ to $1000^{\circ} \mathrm{C}$ and from $612^{\circ} \mathrm{C}$ to $1037^{\circ} \mathrm{C}$, respectively. Extrapolating these results to tensile strain rates employed in the present study (greater than $100 \mathrm{~s}^{-1}$ ), it is expected that no BDT temperature will be observed due to the inherent brittle nature of these alloys.

\section{SUMMARY}

In the present study dynamic yield and flow behavior of Gamma Met PX is investigated under both uniaxial compression and tension loading, and at temperatures ranging from room to $900^{\circ} \mathrm{C}$. The room temperature experiments show that Gamma Met PX is highly rate-sensitive; yield strength as high as $2.2 \mathrm{GPa}$ is observed at strain rates of $3500 \mathrm{~s}^{-1}$. At room temperature, Gamma Met PX shows appreciable strain hardening at all levels of strain rates employed in the study. At elevated temperatures Gamma-Met PX continues to show rate sensitivity of yield stress and the flow stress. The alloy shows little or no thermal softening up to test temperatures of $600^{\circ} \mathrm{C}$ at all strain rates employed in the study. However, an accelerated drop in flow stress is observed beyond test temperatures of $600^{\circ} \mathrm{C}$ at the quasi-static strain rates, and beyond $800^{\circ} \mathrm{C}$ at the higher strain rates employed in the present study. For test temperatures from room up to $800^{\circ} \mathrm{C}$ and at strain rates in excess of $3000 \mathrm{~s}^{-1}$, Gamma-Met PX specimens are observed to pulverize consistently during dynamic compression. However, at test temperatures in excess of $800^{\circ} \mathrm{C}$, the alloy shows better ductility and the failure mode changes from fragmentation to radial cracking. The material does not show any yield anomaly up to $900^{\circ} \mathrm{C}$. 
The results for the quasi-static tensile tests on Gamma-Met PX show negligible effect of test temperature on both yield and the UTS up to $600^{\circ} \mathrm{C}$. However, at test temperatures beyond $600^{\circ} \mathrm{C}$, an accelerated fall in both the stress levels is observed. This fall in strength is accompanied by an increase in the total strain to failure. The room temperature high-strain-rate tensile tests (strain rates in the range 500 and $1000 \mathrm{~s}^{-1}$ ) show negligible strain rate dependence on both yield stress and the flow stress. Moreover, with an increase in test temperature from room to $900^{\circ} \mathrm{C}$, the material shows a drop in both yield stress and the flow stress at all levels of plastic strains. However, it is to be noted that these levels of failure strength and ductility are still higher when compared to those measured for other gamma titanium aluminides alloys, e.g. Ti47 Al-1.5Cr-.5Mn-2.8Nb and Ti-47Al-2Mn-2Nb, under similar test conditions.

\section{ACKNOWLEDGEMENT}

The authors would like to acknowledge financial support from NASA's advanced aeropropulsion research program through grant No. NAG 3-2677. The authors would also like to thank Andreas Venskutonis of Plansee, Austria, for providing the Gamma Met PX material used in the present study. The authors would also like to acknowledge the financial support from the National Science Foundation through grants CMS-9908189 and CMS-0079458 in setting up the elevated temperature test facility at CWRU.

\section{REFERENCES}

$2001 A B A Q U S^{T M}$ (Providence, RI: Hibbit, Karlsson and Sorensen).

Al-Mousawi M. M., Reid S. R. and Deans W. F., 1997. Use of the split Hopkinson pressure bar techniques in high strain rate materials testing. Journal of Mechanical Engineering Science 211(4), 273-292.

Austin C. M., Kelly T. J. and McAllister K. G. C. J. C., 1997. Aircraft Engine applications for gamma titanium aluminides. In: Proceedings of the Second International Symposium on Structural Intermetallics. ed(s): Nathal M. V., Darolia R., Liu C. T., Martin P. L., Miracle D. B., Wagner R. and Yamaguchi M. TMS, Warrendale, PA, pp. 413-425.

Bartels A., Clemens H., Dehm G., Lach E. and Schillinger W., 2002. Strain rate dependence of the deformation mechanisms in a fully lamellar $\gamma-\mathrm{TiAl}$ based alloy. Materials Research and Advanced Techniques 93(3), 180-185.

Bartels A., Koeppe C., Zhang T. and Mecking H., 1995. Yield and work hardening of the TiAl in 
the regime of inverse strain rate and temperature dependence . In: Gamma Titanium Aluminides. ed(s): Y.-W. Kim et al. The Minerals, Metals and Materials Society, pp. 655-663.

Das G. and Clemens H., 1999. Deformation and microstructure of Ti-47Al-2Cr-0.2Si Rolled sheets. In: Gamma Titanium Aluminides. ed(s): Y.-W. Kim et al. The Minerals, Metals and Materials Society, pp. 281-289.

Dimiduk D. M., Miracle D. B., Kim Y.-W. and Mendiratta M. G., 1991. Recent progress in intermetallic alloys for advanced aerospace applications. ISIJ International 31(10), 1223-1234.

Djanarthany S., Viala J.-C. and Bouix J., 2001. An overview of monolithic titanium aluminides based on $\mathrm{Ti}_{3} \mathrm{Al}$ and TiAl. Materials Chemistry and Physics 72, 301-319.

Follansbee P S, 1985. The Hopkinson bar. Mechanical Testing, Metals Handbook. vol 8, 9 edn ASM, Metals Park, Ohio, pp 198-217.

Follansbee P. S. and Frantz C., 1983. Wave propagation in the split Hopkinson Pressure bar. Journal of Engineering Materials and Technology 105, 61-66.

Gardiner P., Miguelez H., Cortes R., LePetitcorps Y, Dodd B. and Navarro C., 1997. Dynamic characterization of TiAl intermetallics in hot compression. Journal De Physique IV C3 7, 593597.

Gray G T, 2000. High strain rate testing of materials: The split Hopkinson pressure bar. Methods in Materials Research. John Wiley Press,

Harding J., Wood E. D. and Cambell J. D., 1960. Tensile testing of materials at impact rates of strain. Journal of Mechanical Engineering Science 2, 88-96.

Huang S.-C. and Hall E. L., 1991. Plastic deformation and fracture of binary TiAl base alloys. Metallurgical Transactions A 22A, 427-439.

Jin Z., Cady C., Gray III G. and Kim Y.-W., 1995. Mechanical response and microcrack formation in a fine-grained Duplex TiAl at different strain rates and temperature. In: Gamma Titanium Aluminides. ed(s): Y.-W. Kim et al. The Minerals, Metals and Materials Society, pp. 101-110.

Jin Z., Gray G. T., Kim Y.-W. and Yamaguchi M., 1997. Mechanical behavior and microcrack formation in $\gamma$-TiAl as a function of strain rate and temperature. In: Proceedings of the Second International Symposium on Structural Intermetallics. ed(s): Nathal M. V., Darolia R., Liu C. T., Martin P. L., Miracle D. B., Wagner R. and Yamaguchi M. TMS, Warrendale, PA, pp. 225-233.

Kim Y.-W, 1989. Intermetallic alloys based on gamma titanium aluminides. Journal of Metals 41(7), 24-30.

Kim Y.-W. and Dimiduk D. M., 1991. Progress in the understanding of gamma titanium aluminide. JOM 43(8), 40-47. 
Kumpfert J., Kim Y.-W. and Dimiduk D. M., 1995. Effect of microstructure on fatigue and tensile properties of the gamma TiAl alloy Ti-46.5Al-3.0Nb-2.1Cr-0.2W. Materials Science and Engineering A 192/193, 465-473.

LeHolm R., Clemens H. and Kestler H., 1999. Powder metallurgy (PM) gamma based titanium aluminide structures for use in various high temperature aerospace applications. In: Gamma Titanium Aluminides. ed(s): Y.-W. Kim et al. The Minerals, Metals and Materials Society, pp. 25-33.

Lennon A. M. and Ramesh K. T., 1998. A Technique for Measuring the Dynamic Behavior of Materials at High Temperatures. International Journal of Plasticity 14, 1279-1292.

Lindholm U. S. and Yeakley L. M., 1968. High strain-rate testing: tension and compression. Experimental Mechanics 8, 1-9.

Liu C. T., Maziasz P. J., Clemens D. R., Schneibel J. H., Sikka V. K., Nieh T. G., Wright J. and Walker L. R., 1995. Room and Elevated temperature mechanical properties of PM TiAl alloy Ti47Al-2Cr-2Nb. In: Gamma Titanium Aluminides. ed(s): Y.-W. Kim et al. The Minerals, Metals and Materials Society, 679-688.

Lui C. T. and Stiegler J. O., 2002. Ordered Intermetallics. Metals Handbook. vol 2, $10^{\text {th }}$ edn American Society of Materials, 913-42.

Maloy S. A. and Gray III G. T., 1996. High strain rate deformation of Ti-48Al-2Nb-2Cr. Acta Materialia 44(5), 1741-1756.

Millett J. C. F., Gray G. T. and Boume N. K., 2000. Lateral stress measurements and shear strength in shock loaded $\gamma$-TiAl alloy. Journal De Physique IV 10, 781-785.

Morris M. A., 1994. Dislocation configurations in two phase TiAl alloys III. Mechanisms producing anomalous flow stress dependence on temperature. Philosophical Magazine A 69(1), 129-150.

Nemat-Nasser S., Issacs J. B. and Starrett J. E., 1991. Hopkinson bar techniques for dynamic recovery experiments. Proceedings of Royal Society of London A435, 371-391.

Nicholas T., 1981. Tensile testing of materials at high rates of strain. Experimental Mechanics, 177-185.

Nicholas T and Bless S J, 1991. High strain rate testing. Metals Handbook. vol 8, 13 edn Amercan Society of Materials, pp 208-14.

Recina V, 2000. Mechanical Properties of Gamma Titanium Aluminides 1577: Chalmers Technical University.

Rosenberg Z., Dawicke D., Strader E. and Bless S. J., 1986. A new technique for heating specimens in split-Hopkinson bar experiments using induction coil heaters. Experimental Mechanics 26(2), 275-278. 
Staab G. H. and Gilat A., 1991. A direct tension split Hopkinson bar for high strain rate testing. Experimental Mechanics 31(3), 232-235.

Vaidya R. U., Jin Z., Cady C., Gray III G. and Butt D. P., 1999. A comparative study of the strain rate and temperature dependent compression behavior of Ti-46.5Al-3Nb-2Cr- $0.2 \mathrm{~W}$ and $\mathrm{Ti}-$ 25Al-10Nb-3V-1Mo Intermetallic alloys. Scripta Materialia 41(6), 569-574.

Venskutonis K. R., 2000. Gamma-met 100 Titanium aluminide sheet production and component fabrication. Preparing for the Future 10(2), 2-3.

Wang Y., Dongliang L. and Law C., 1999a. Brittle to Ductile transition temperature and its strain rate sensitivity in a two phase titanium aluminide with near lamellar microstructure. Journal of Materials Science 34, 3155-3159.

Wang Y., Dongliang L. and Kim Y.-W., 1999b. High strain rate tensile properties of TiAl alloy in duplex and fully lamellar microstructural forms. Transactions of Non-Ferrous Metals Society of China 9(3), 437-441.

Wang Y., Lin D., Zhou Y. and Law C., 1999c. Dynamic tensile properties of Ti-47Al-2Mn-2Nb alloy. Journal of Materials Science 34, 509-513.

Wang Y., Dongliang L. and Law C., 2000. The affect of boron addition on brittle to ductile transition temperature and its strain rate sensitivity in Gamma Titanium Aluminide. Journal of Materials Science 35, 3083-3087.

Wright P. K., 1993. On ductility and toughness requirements for intermetallics in aircraft engines. In: Structural Intermetallics. ed(s): Darolia R. The Minerals, Metals and Materials Society.

Yamagushi M. I. H., 1993. TiAl compounds for structural applications. In: Structural Intermetallics. The Minerals, Metals and Materials Society, 127-142.

Young-Won Kim, 1989. Intermetallic alloys based on gamma titanium aluminides. Journal of Metals 41(7), 24-30. 